IZA DP No. 9662

Intergenerational Transmission of Skills and Differences in Labor Market Outcomes for Blacks and Whites

Tsunao Okumura

Emiko Usui

January 2016

Forschungsinstitut zur Zukunft der Arbeit Institute for the Study of Labor 


\title{
Intergenerational Transmission of Skills and Differences in Labor Market Outcomes for Blacks and Whites
}

\author{
Tsunao Okumura \\ Yokohama National University
}

Emiko Usui

Hitotsubashi University

and IZA

Discussion Paper No. 9662

January 2016

IZA

P.O. Box 7240

53072 Bonn

Germany

Phone: +49-228-3894-0

Fax: +49-228-3894-180

E-mail: iza@iza.org

Any opinions expressed here are those of the author(s) and not those of IZA. Research published in this series may include views on policy, but the institute itself takes no institutional policy positions. The IZA research network is committed to the IZA Guiding Principles of Research Integrity.

The Institute for the Study of Labor (IZA) in Bonn is a local and virtual international research center and a place of communication between science, politics and business. IZA is an independent nonprofit organization supported by Deutsche Post Foundation. The center is associated with the University of Bonn and offers a stimulating research environment through its international network, workshops and conferences, data service, project support, research visits and doctoral program. IZA engages in (i) original and internationally competitive research in all fields of labor economics, (ii) development of policy concepts, and (iii) dissemination of research results and concepts to the interested public.

IZA Discussion Papers often represent preliminary work and are circulated to encourage discussion. Citation of such a paper should account for its provisional character. A revised version may be available directly from the author. 


\section{ABSTRACT}

\section{Intergenerational Transmission of Skills and Differences in Labor Market Outcomes for Blacks and Whites*}

This paper investigates, theoretically and empirically, differences between blacks and whites in the U.S. concerning the intergenerational transmission of occupational skills and the effects on sons' earnings. The father-son skill correlation is measured by the correlation coefficient (or cosine of the angle) between the father's skill vector and the son's skill vector. The skill vector comprises an individual's occupational characteristics from the Dictionary of Occupational Titles (DOT). According to data from the U.S. National Longitudinal Survey of Youth (NLSY79), white sons earn higher wages in occupations that require skills similar to those of their fathers, whereas black sons in such circumstances incur a wage loss. A large portion of the racial wage gap is explained by the father-son skill correlation. However, a significant unexplained racial wage gap remains at the lower tail of the wage distribution.

JEL Classification: J62, J24, J15

Keywords: multidimensional skills, intergenerational transmission, occupational characteristics, black-white differences

Corresponding author:

Emiko Usui

Institute of Economic Research

Hitotsubashi University

Kunitachi, 186-8603 Tokyo

Japan

E-mail: usui@ier.hit-u.ac.jp

\footnotetext{
${ }^{*}$ For helpful comments and suggestions, we would like to thank two anonymous referees, as well as Joseph Altonji, Lorenzo Cappellari, Hidehiko Ichimura, Seik Kim, Hideo Owan, Solomon Polachek, Kathryn Shaw, Konstantinos Tatsiramos, and participants in meetings held at Hitotsubashi University, IZA, Keio University, Oakland University, Osaka University, the Trans-Pacific Labor Seminar (TPLS), the University of Michigan, and the University of Tokyo, and at annual meetings of the North American Econometric Society, the European Association of Labour Economists, the Japanese Economic Association, and the Society of Labor Economists. Remaining errors are our own. An earlier version of the article was circulated under the title "Intergenerational Correlations of Skills." This research is supported by JSPS grants 22000001 (Usui) and 15H05692 (Okumura and Usui).
} 


\section{Introduction}

Skill disparities between black and white Americans have historically been substantial, a fact attributable to the difficulties that blacks have faced as a result of racial segregation and discrimination. Although the skill gaps between the two groups - as measured by educational attainment and test scores - declined in the 1970s and 1980s due to school desegregation and improvements in school quality for blacks, significant gaps remain, and they are important determinants of earnings differences between blacks and whites. ${ }^{1}$ In light of the fact that parents often pass skills and traits onto their children through environment and education, it is essential in this context to estimate to what extent black-white differences in parents' skills contribute to the black-white differences in skills and earnings among their children.

The seminal work of Neal and Johnson (1996) shows that scores on the Armed Forces Qualification Test (AFQT), a measure of cognitive skills, explain much of the wage gap between black and white young adults. Their results suggest that the black-white wage gap primarily reflects a difference in cognitive skills that exists before young men enter the labor market. To clarify the source of this skill gap, Neal (2006) presents an intergenerational model to demonstrate that the black-white difference in the parents' costs of investing in their children's skill acquisition can contribute to the black-white gaps in skills and wages among children. However, recent empirical studies have found that cognitive skills are not the only skill dimensions that are important in determining wages (Ingram and Neumann, 2006; Bacolod and Blum, 2010). For example, Bacolod and Blum (2010) find that the wage returns to cognitive and people skills more than doubled during the 1968-1990 period, with cognitive skills becoming more complementary to motor skills and especially people skills.

In this paper, we first extend Neal's (2006) intergenerational model to encompass cognitive, people, and motor skills, along with skills associated with physical strength. We then investigate how the black-white differences in the fathers' cost of investing in cognitive skills affect their sons' skill attainment and earnings. For the empirical analysis, we pair information about fathers and sons from the U.S. National Longitudinal Survey of Youth (NLSY79) with the occupational characteristics from the Dictionary of Occupational Titles (DOT) to construct multidimensional skill vectors for fathers and sons. First, we find that white sons earn higher wages in occupations that require skills similar to their fathers' skills, whereas

\footnotetext{
${ }^{1}$ See Altonji and Blank (1999) for a comprehensive survey of the literature concerning black-white differences in the U.S. labor market.
} 
black sons in such circumstances incur a wage loss. This finding implies a positive transfer of skill-related human capital for whites but not for blacks. Second, we find that a significant portion of the black-white wage gap is attributable to the wage premium earned by white sons and the wage penalty incurred by black sons for working in occupations that require skills similar to their fathers' occupations.

We begin by extending the human capital models of Becker and Tomes (1976) and Laband and Lentz (1983) to a model in which fathers and sons invest in two types of human capital: T skills that represent cognitive skills, and $\mathbf{M}$ skills that represent other skills such as people skills, motor skills, and physical strength. For each individual, we construct a skill vector that is composed of the individual's $T$ skills and $M$ skills. We measure the closeness between the father's and the son's skill vectors by the cosine of the angle between these two vectors. The model predicts that an increase in skill inheritance from fathers to sons leads to a greater skill correlation between them, because of the cost savings for sons from "inheriting" part of their fathers' skills.

We then apply the model to examine black-white differences in the effects of the fathers' relative costs of investing in their $T$ skills as compared to their $M$ skills on the sons' skill combinations and earnings. First, we assume that the relative returns to $T$ skills as compared to $M$ skills increased from the fathers' to the sons' generation. We do this because empirical studies such as Ingram and Neumann (2006) have found a large rise in the returns to mathematical and verbal ability since the early 1980s and a steady decline in the returns to manual skills. ${ }^{2}$ Second, we assume that black fathers paid a greater relative cost to acquire $T$ skills as compared to $M$ skills than did white fathers, and that black sons' costs of investing in $T$ skills declined, even though some black sons still pay a greater cost to acquire $T$ skills. These assumptions reflect school segregation and difficulties that blacks experienced in accessing quality schools before the Supreme Court ruling on Brown v. Board of Education in 1954. Afterwards, however, the black-white disparity in costs of investing in cognitive skills gradually narrowed for blacks because of school desegregation and improvements in school quality for blacks, as documented in Guryan (2004), Neal (2006), Reber (2010), and Johnson (2014), among others. ${ }^{3}$ We then present how the black-white differences in the fathers' costs

\footnotetext{
${ }^{2}$ The chronology of these findings overlaps the years in our NLSY79 sample, where information for fathers is from the 1970s and for sons is from the 1990s. Also, see Katz and Autor (1999) and Murnane, Willett, and Levy (1995) regarding the rise in the returns to schooling and cognitive skills.

${ }^{3}$ The NLSY79 respondents (sons) were born in the years 1957-64, and therefore after the 1954 Supreme Court ruling. However, about half of the fathers in the NLSY79 sample were born in the 1930s, and therefore received their formal education before the 1954 Supreme Court ruling, i.e., the period when segregation and
} 
of investing in cognitive skills and the increase over time in the returns to cognitive skills contribute to differences between black and white sons in the skill combinations and earnings. The model predicts that white sons who work in occupations requiring skill sets similar to those of their fathers earn higher wages because they inherit part of their fathers' skill sets, thus reducing the costs of acquiring skills that pay higher wages. However, among blacks, sons who earn higher wages are those who work in occupations requiring skill sets different from those of their fathers. Because of their fathers' higher costs involved in acquiring cognitive skills, the skills sets that the black sons inherit from their fathers are away from those that pay higher wages to the sons. For this reason, the black sons have to acquire different skill sets from those of their fathers in order to seek higher wages. The wage gap between black and white sons is therefore attributable to (1) white sons' wage gains resulting from their cost savings from the intergenerational skill transfer, (2) black sons' wage loss resulting from their costs in moving away from their fathers' occupations, and (3) black sons' wage loss resulting from working in occupations that require skills similar to their fathers'. The model also predicts that when there is complementarity between cognitive skills and other skills in the returns to wages for fathers and sons (see Bacolod and Blum (2010)), the black-white difference in the fathers' costs of investing in cognitive skills further widens the black-white wage gap for sons.

These predictions from the theoretical model are then compared with the empirical analysis using the sample of fathers and sons from the NLSY79, which includes fathers who were in their forties during the 1970s and sons (NLSY79 respondents) who were in their late twenties to late thirties in 1993 and 2000. For each individual, we construct a multidimensional skill vector by measures of skill requirements drawn from the Dictionary of Occupational Titles (DOT). The DOT characterizes each occupation's requirements, using ranges of cognitive skills, people skills, motor skills, and skills associated with physical strength. Skill correlation between father and son is measured by the cosine of the angle of their respective skill vectors. Specifically, we compute the correlation coefficient between the father's skill vector and the son's skill vector.

We establish three facts about the distribution of father-son skill correlation. First, in a hypothetical situation where father-son pairs are randomly matched, the median of the distribution of skill correlation is positive for blacks but it is close to zero for whites. Second, the skill correlation for actual father-son pairs, which goes beyond the skill correlation discrimination were more severe in the U.S. 
under random matching of fathers and sons, is greater for whites than for blacks. Third, the correlation coefficients among whites are higher in families with highly educated fathers; however, among blacks the correlation coefficients are higher for not only those families with highly educated fathers but also for those families with the least educated fathers. These facts imply that father-son skill correlation for blacks arises from the limited skill sets available to them, whereas the skill correlation for whites arises from fathers' and sons' choosing similar occupations from a wider variety of skill sets.

We then estimate the sons' wage effects of skill-related human capital transfers (obtained from working in occupations that require skills similar to those of their fathers) and of nepotism (obtained from working in the same occupation as their fathers). Neal and Johnson (1996) find that differences in cognitive skills explain much of the wage gap between black and white men, yet a significant unexplained wage gap remains. We therefore include as regressors in Neal and Johnson's wage equation (1) the correlation coefficient between the father's and the son's skill vectors, (2) a dummy for whether father and son work in the same occupation, and (3) fathers' education and DOT skill variables.

We present the following four findings and discuss their implications. First, white sons earn a wage premium for working in occupations requiring skills similar to their fathers', whereas black sons in such circumstances incur a wage penalty. This implies a positive skill transfer from fathers to sons for whites, but an insufficient skill acquisition for black sons due to their fathers' greater costs of investing in cognitive skills. Second, by including the correlation coefficient between father-son skill vectors in the wage regression, the unexplained black-white wage gap, after controlling for cognitive skills, is reduced to 30 percent. A significant portion of the black-white wage gap is therefore attributable to the wage premium earned by white sons and the wage penalty paid by black sons for working in occupations that require skills similar to their fathers'. Third, from the quantile wage regression, we find that the blackwhite wage gap in the middle of the wage distribution for sons arises from the black-white differences in the effect of skill transfer from their fathers, whereas the black-white wage gap in the lower tail of the wage distribution arises from the unexplained black-white wage gap. This result indicates that blacks in the lower tail of the wage distribution are hampered in achieving economic success by unexplained difficulties (such as discrimination), while blacks in the middle of the wage distribution are hampered by the negative effect of skill transfer from their fathers. Fourth, evidence of nepotism for sons is found in whites, since they earn higher wages for working in the same occupation as their fathers. 
The paper proceeds as follows. Section 2 presents an intergenerational model with multidimensional skills. Section 3 describes the data used in the analysis and includes descriptive statistics for the NLSY79 sample. Section 4 measures the multidimensional-skill correlation between a father and a son, and Section 5 examines sons' economic returns or penalties from working in occupations similar to those of their fathers. Section 6 concludes the paper.

\section{Model of Intergenerational Skill Transfer}

The seminal works of Ishikawa (1975) and Becker and Tomes (1976) study the intergenerational transmission of human capital from parent to child. Laband and Lentz (1983) extend those intergenerational models to include a son following his father's occupation. They show that when a son adopts a father's occupation, part of the cost of schooling is saved, but a cost for personal training is incurred. When the personal-training cost is less than the school-training cost, the son works in the same job as his father.

Extending these previous studies, we consider the intergenerational transmission of skills that are multidimensional, and we measure the father-son skill correlation by the angle (or cosine of the angle) of the multidimensional skill vectors between father and son. In our model, each family has one father and one son. The father chooses the amount of his skills to maximize his utility. A portion of those skills is then inherited by the son. The son's skill holdings are the sum of his inherited and personally acquired skills. Given his inherited skills, the son chooses the amount of skills that he personally acquires in order to maximize his utility. Because of inherited skills, father and son tend to show similar combinations of skills. ${ }^{4}$

For simplicity, we set up a model of a two-dimensional skill transfer. Each occupation requires a skill vector $(T, M)$, where $T$ stands for cognitive skills and $M$ stands for other skills, such as people skills, motor skills, and physical strength. Let the father's initial skill endowment be $(0,0)$, and the father invests in a skill vector $\Psi_{F}=\left(T_{F}, M_{F}\right)$. An $x$ portion of the father's skill vector is transferred to the son by means of the educational environment at home and/or genes $(0 \leq x \leq 1) .^{5}$ The son's skill holdings are determined by (1) the father's

\footnotetext{
${ }^{4}$ In an alternative analysis, we assumed that an altruistic father maximizes family utility (which consists of the father's and the son's combined utilities) à la Ishikawa (1975) and Becker and Tomes (1976). An altruistic father chooses his skills not only to increase his own wages but also to increase his son's wages by transferring his skills to the son. Therefore, parental altruism enhances intergenerational skill correlation. Altruism introduces additional complications but does not change the main results. Details are available from the authors upon request.

${ }^{5}$ In our analysis, we do not separate nature and nurture effects, but adoption data have been used in other
} 
transfer to him of $\left(x T_{F}, x M_{F}\right)$ and (2) his own investment $\left(T^{*}, M^{*}\right)$. Thus, the son's skill vector is

$$
\Psi_{S}=\left(T_{S}, M_{S}\right)=\left(x T_{F}+T^{*}, x M_{F}+M^{*}\right)
$$

where $T_{F}, M_{F}, T^{*}$, and $M^{*}$ are nonnegative. Wages are based on a skill vector: $\omega_{F}\left(T_{F}, M_{F}\right)$ for the father and $\omega_{S}\left(T_{S}, M_{S}\right)$ for the son, which are strictly increasing in each argument and are concave. The cost of investing in skills depends on the amount invested by each individual: $\gamma_{F}\left(T_{F}, M_{F}\right)$ for the father and $\gamma_{S}\left(T^{*}, M^{*}\right)$ for the son, which are strictly increasing in each argument and are convex.

The father solves the following problem:

$$
\begin{aligned}
& \max _{\left\{T_{F}, M_{F}, c_{F}\right\}} u_{F}\left(c_{F}\right), \\
& \text { subject to: } \quad 0 \leq c_{F} \leq \omega_{F}\left(T_{F}, M_{F}\right)-\gamma_{F}\left(T_{F}, M_{F}\right) ;
\end{aligned}
$$

and the son solves the following problem:

$$
\begin{array}{ll}
\max _{\left\{T^{*}, M^{*}, c_{S}\right\}} u_{S}\left(c_{S}\right), \\
\text { subject to: } & \left(T_{S}, M_{S}\right)=\left(x T_{F}+T^{*}, x M_{F}+M^{*}\right) \\
& 0 \leq c_{S} \leq \omega_{S}\left(T_{S}, M_{S}\right)-\gamma_{S}\left(T^{*}, M^{*}\right),
\end{array}
$$

where $c_{F}$ is the father's consumption and $u_{F}$ is his utility, while $c_{S}$ is the son's consumption and $u_{S}$ is his utility. Figure 1 illustrates the father's and son's equilibrium skill vectors. ${ }^{6}$ The horizontal axis represents $T$ skills, and the vertical axis represents $M$ skills. The father acquires the skill vector $\Psi_{F}$, so that at point $\Psi_{F}=\left(T_{F}, M_{F}\right)$ the father's iso-wage and iso-cost curves are tangent to each other. Since the son inherits an $x$ portion of the father's skills, the origin of the son's iso-cost curve is $\left(x T_{F}, x M_{F}\right)$. However, the origin of the son's iso-wage curve is $(0,0)$. The son acquires the skill vector $\Psi_{S}$, so that at point $\Psi_{S}=\left(T_{S}, M_{S}\right)$ the son's iso-wage and iso-cost curves are tangent to each other.

studies to separate these effects on education, income, and/or behavioral outcomes (Björklund, Lindahl, and Plug, 2006; Sacerdote, 2007).

${ }^{6}$ Under the assumption of interior solutions, the first-order conditions for the father's problem (2) and the son's problem (3) are described as:

$$
\left\{\begin{array}{l}
\frac{\partial \omega_{F}\left(T_{F}, M_{F}\right)}{\partial T_{F}}=\frac{\partial \gamma_{F}\left(T_{F}, M_{F}\right)}{\partial T_{F}}, \quad \frac{\partial \omega_{F}\left(T_{F}, M_{F}\right)}{\partial M_{F}}=\frac{\partial \gamma_{F}\left(T_{F}, M_{F}\right)}{\partial M_{F}}, \\
\frac{\partial \omega_{S}\left(T_{S}, M_{S}\right)}{\partial T^{*}}=\frac{\partial \gamma_{S}\left(T^{*}, M^{*}\right)}{\partial T^{*}}, \quad \frac{\partial \omega_{S}\left(T_{S}, M_{S}\right)}{\partial M^{*}}=\frac{\partial \gamma_{S}\left(T^{*}, M^{*}\right)}{\partial M^{*}}, \\
\left(T_{S}, M_{S}\right)=\left(x T_{F}+T^{*}, x M_{F}+M^{*}\right), \\
c_{F}=\omega_{F}\left(T_{F}, M_{F}\right)-\gamma_{F}\left(T_{F}, M_{F}\right), \quad c_{S}=\omega_{S}\left(T_{S}, M_{S}\right)-\gamma_{S}\left(T^{*}, M^{*}\right) .
\end{array}\right.
$$


To measure the skill correlation between father and son, we compute the cosine of the angle between the father's skill vector $\Psi_{F}=\left(T_{F}, M_{F}\right)$ and the son's skill vector $\Psi_{S}=\left(T_{S}, M_{S}\right)$. Let $\theta$ be the angle between these two skill vectors. Then

$$
\cos \theta=\frac{T_{F} T_{S}+M_{F} M_{S}}{\sqrt{T_{F}^{2}+M_{F}^{2}} \sqrt{T_{S}^{2}+M_{S}^{2}}} .
$$

To solve explicitly for equilibrium, the wage function is given by the Cobb-Douglas form:

$$
\begin{aligned}
& \omega_{F}\left(T_{F}, M_{F}\right)=T_{F}^{\delta} M_{F}^{1-\delta} \text { for the father }(\delta \in(0,1)) ; \\
& \omega_{S}\left(T_{S}, M_{S}\right)=\sqrt{T_{S} M_{S}} \text { for the son. }
\end{aligned}
$$

The assumption of complementarity between skills in the returns to wages is supported empirically by Bacolod and Blum (2010), who find evidence of complementarity between cognitive and people skills, between cognitive and motor skills, and between motor skills and physical strength during specified time periods in the U.S.

The cost function is specified as

$$
\begin{aligned}
& \gamma_{F}\left(T_{F}, M_{F}\right)=a_{F} T_{F}^{2}+b M_{F}^{2} \text { for the father; } \\
& \gamma_{S}\left(T^{*}, M^{*}\right)=a_{S} T^{* 2}+b M^{* 2} \text { for the son, }
\end{aligned}
$$

where $a_{F}, a_{S}$, and $b$ are positive. The cost of acquiring skills for the father and the son is represented by the sum of the square of $T$ and $M$ skills invested by each individual, which are weighted by $a_{F}$ and $b$ for the father and by $a_{S}$ and $b$ for the son. ${ }^{7}$

After solving for the equilibrium outcomes, we formulate four propositions that will be applied to study the relationship between (1) black-white differences in the father's cost of acquiring cognitive skills and (2) black-white differences in the son's economic outcomes. These propositions are stated and discussed below, and their proofs are provided in the appendix.

\section{P1: Effect of skill inheritance (x)}

This proposition examines the effects of skill inheritance $(x)$ on the father-son skill correlation $(\cos \theta)$ and on the son's wage $\left(\omega_{S}\right)$ :

\footnotetext{
${ }^{7}$ Note that the wage elasticity of $T_{S}$ and $M_{S}$ is fixed to $1 / 2$ for the son in Equation (5); and the cost parameter of $M$ skills is fixed to $b$ for both father and son in Equation (6). We make this simplification because the objective is to analyze the effects on the equilibrium outcomes of the relative costs of $T$ skills compared to those of $M$ skills (i.e., $a_{F} / b$ for the father and $a_{S} / b$ for the son), when the returns to $T$ skills are greater in the son's generation than in the father's generation $(\delta<1 / 2)$, which will be assumed later in Equation (9).
} 
$\begin{cases}\mathrm{P} 1(\mathrm{i}): & \partial \cos \theta / \partial x \geq 0 \quad\left(\text { the equality holds if } a_{S} /(1-\delta)=a_{F} / \delta\right) . \\ \mathrm{P} 1(\mathrm{ii}): & \partial \omega_{S}\left(T_{S}, M_{S}\right) / \partial x>0 .\end{cases}$

P1(i) states that skill inheritance $(x)$ causes a skill correlation between father and son. We use Figure 1 as an example to illustrate this proposition. In Figure 1, the origin of the son's iso-wage curve is $(0,0)$, whereas that of the son's iso-cost curve is $\left(x T_{F}, x M_{F}\right)$. Point $A$ is the point at which the son's iso-wage and iso-cost curves are tangent to each other in the case of no skill inheritance $(x=0)$. When $x$ is positive, as shown in Figure 1, the vector $\left(x T_{F}, x M_{F}\right)$ is on the father's skill vector $\Psi_{F}$ and is above the line $O A$. As a result, the son's skill vector $\Psi_{S}$ is above the line $O A$; specifically, $\Psi_{S}$ lies between vector $\Psi_{F}$ and line $O A$. Since the angle between $\Psi_{F}$ and $\Psi_{S}$ is smaller than the angle between $\Psi_{F}$ and $O A$, it follows that skill inheritance induces a skill correlation between father and son. P1(ii) shows that the inheritance of higher-degree skills raises the son's wages because of the son's greater cost savings in obtaining skills.

From P1(i) and P1(ii), if $x$ varies and all else is held constant, there will be a positive relationship between the father-son skill correlation $(\cos \theta)$ and the son's wages $\left(\omega_{S}\right) .^{8}$

\section{P2: Effect of son's cost of investing in T skills ( $\left.a_{S}\right)$}

This proposition studies the effect of the son's cost of investing in $T$ skills $\left(a_{S}\right)$ on the father-son skill correlation $(\cos \theta)$ and on the son's wage $\left(\omega_{S}\right)$ :

$$
\begin{cases}\mathrm{P} 2(\mathrm{i}): & \partial \cos \theta / \partial a_{S}>0, \text { if } a_{S} /(1-\delta)<a_{F} / \delta \\ \mathrm{P} 2(\mathrm{ii}): & \partial \omega_{S}\left(T_{S}, M_{S}\right) / \partial a_{S}<0\end{cases}
$$

We use Figure 1 to illustrate P2(i). When $a_{S} /(1-\delta)<a_{F} / \delta$, the slope of the son's skill vector $\left(M_{S} / T_{S}\right)$ is smaller than that of the father's $\left(M_{F} / T_{F}\right)$, as can be seen in Figure 1. ${ }^{9}$ When the son's cost of investing in $T$ skills increases, his acquisition of both $T$ and $M$ skills decreases; the decline in his acquisition of $T$ skills is larger than that of $M$ skills. Thus, the slope of the son's skill vector $\left(M_{S} / T_{S}\right)$ increases and the angle between the son's and the

\footnotetext{
${ }^{8}$ In the model, we assume that the degree of skill transfer $x$ is identical between $T$ and $M$ skills. However, we can relax this assumption so that the father's $T$ and $M$ skills are transferred to the son at $x_{1}$ and $x_{2}$, respectively. In this case, the son's skill vector is $\Psi_{S}=\left(T_{S}, M_{S}\right)=\left(x_{1} T_{F}+T^{*}, x_{2} M_{F}+M^{*}\right)$. $P 1$ holds if the son's endowment $\left(x_{1} T_{F}, x_{2} M_{F}\right)$ is located in the area enclosed by $O A, O B$, and $\operatorname{arc} A B$ in Figure 1.

${ }^{9}$ In the section below, in which we study black-white differences in sons' economic outcomes, we assume that the relative value of returns to the costs of acquiring $T$ skills compared to those of $M$ skills is greater for the son $\left(\frac{0.5 / a_{S}}{0.5 / b}\right)$ than for the father $\left(\frac{\delta / a_{F}}{(1-\delta) / b}\right)$; that is, $a_{S} /(1-\delta)<a_{F} / \delta$.
} 
father's skill vectors is smaller. P2(ii) shows that an increase in the son's cost of investing in $T$ skills reduces his holdings of $T$ and $M$ skills and, consequently, his wages.

From P2(i) and P2(ii), we see that if the son's cost of investing in $T$ skills varies and all else is held constant, there will be a negative relationship between the father-son skill correlation and the son's wages when $a_{S} /(1-\delta)<a_{F} / \delta$.

\section{P3: Effect of father's cost of investing in T skills ( $\left.a_{F}\right)$}

This proposition studies the effect of the father's cost of investing in $T$ skills $\left(a_{F}\right)$ on the father-son skill correlation $(\cos \theta)$ and on the son's wage $\left(\omega_{S}\right)$ :

$$
\left\{\begin{array}{l}
\text { P3(i): } \quad \partial \cos \theta / \partial a_{F}<0, \text { if } a_{S} /(1-\delta)<a_{F} / \delta . \\
\text { P3(ii): } \left.\quad \partial \omega_{S}\left(T_{S}, M_{S}\right) / \partial a_{F} \leq 0 \text { (the equality holds if } x=0\right) .
\end{array}\right.
$$

P3(i) shows that a son whose father paid a higher cost to invest in $T$ skills chooses a skill vector further away from the father's skill vector, if $a_{S} /(1-\delta)<a_{F} / \delta$, as shown in Figure 1. When the father's cost of investing in $T$ skills increases, the decline in his acquisition of $T$ skills $\left(T_{F}\right)$ is greater than that of $M$ skills $\left(M_{F}\right)$, so that the slope of the father's skill vector $\left(M_{F} / T_{F}\right)$ increases. Subsequently, through father-son skill transfer, the decline in the son's inheritance of $T$ skills $\left(x T_{F}\right)$ is greater than that of $M$ skills $\left(x M_{F}\right)$. To compensate for the decline in the son's inheritance of $T$ skills $\left(x T_{F}\right)$, the son increases his $T$ skill acquisition $\left(T^{*}\right)$, such that the slope of his skill-acquisition vector $\left(M^{*} / T^{*}\right)$ decreases. As a result, the angle between the father's skill vector $\left(T_{F}, M_{F}\right)$ and the son's skill vector $\left(T_{S}, M_{S}\right)$ is wider.

P3(ii) shows that if a father pays a higher cost to invest in $T$ skills, then the son's wages are negatively affected. This is because higher costs reduce the father's skill holdings, and subsequently reduce the son's skill holdings through father-son skill transfer.

From P3(i) and P3(ii), we see that if the father's cost of investing in $T$ skills varies and all else is held constant, the relationship between the father-son skill correlation and the son's wages is positive when $a_{S} /(1-\delta)<a_{F} / \delta$.

\section{P4: Effect of complementarity between $T$ and $M$ skills on son's wage}

P3(ii) shows that the high cost for the father to invest in $T$ skills reduces the son's wages through father-son skill transfer. P4 further shows that its effect on the son's wages is enhanced when there is complementarity between $T$ and $M$ skills in the returns to wages for 
father and son:

$$
\frac{\partial \omega_{S}\left(T_{S}, M_{S}\right)}{\partial a_{F}} \leq \frac{\partial \omega_{S}\left(T_{S}, M_{S}\right)}{\partial T_{S}} \frac{\partial T_{S}}{\partial a_{F}} \leq \frac{\partial \omega_{S}\left(T_{S}, M_{S}\right)}{\partial T_{S}} \frac{\partial T_{S}}{\partial T_{F}} \frac{\partial T_{F}}{\partial a_{F}} \leq 0,
$$

where the equalities hold if $x$ is equal to zero. Because of complementarity between $T$ and $M$ skills in the father's wage, the father's high cost of investing in $T$ skills inhibits not only his acquisition of $T$ skills but also his acquisition of complementary $M$ skills. ${ }^{10}$ Having inherited fewer $T$ and $M$ skills, the son's holdings of such skills are smaller. Because of complementarity between $T$ and $M$ skills in the son's wage, the son's smaller holdings of both skills depress his wage more than the smaller holdings of only $T$ skills. In Equation (7), the quantity $\frac{\partial \omega_{S}\left(T_{S}, M_{S}\right)}{\partial T_{S}} \frac{\partial T_{S}}{\partial T_{F}} \frac{\partial T_{F}}{\partial a_{F}}$ represents the son's wage decline when (i) an increase in $a_{F}$ reduces only the son's $T$ skills through a decrease in the father's $T$ skill transfer, and (ii) the effect of complementary $M$ skills for father and son on the son's wages is ignored. Also, the quantity $\frac{\partial \omega_{S}\left(T_{S}, M_{S}\right)}{\partial T_{S}} \frac{\partial T_{S}}{\partial a_{F}}$ represents the son's wage decline when (i) an increase in $a_{F}$ reduces only the son's $T$ skill acquisition, and (ii) the effect of complementary $M$ skills for only the son is ignored. The numerical results in Appendix A4 show that the former quantity explains only 30 to 75 percent of the total decline of the son's wages $\left(\frac{\partial \omega_{S}\left(T_{S}, M_{S}\right)}{\partial a_{F}}\right)$, and the latter quantity explains only 50 to 75 percent. Therefore, skill complementarity augments the decline in the son's wage.

Propositions P1, P2, P3, and P4 are now used to understand the effect on the son's economic outcomes of black-white differences in the father's cost of investing in cognitive skills. Consider three types of families: the B1-type and the B2-type, which are black, and the W-type, which is white. Assume that fathers in the B1 and B2 families pay a higher cost than fathers in $\mathrm{W}$ families to invest in cognitive skills $(T)$. However, the cost of investing in these skills is lower for sons in B2 families than in B1 families because B2 families reflect the improvement in school quality for blacks during the 1970s and 1980s, as documented by Hedges and Nowell (1998) and Neal (2006), among others. ${ }^{11}$ In contrast, W-type families pay a lower cost to invest in cognitive skills $(T)$ than do black families, and their cost structure

\footnotetext{
${ }^{10}$ Since the iso-wage curve is Cobb-Douglas and the iso-cost curve is elliptical, an increase in $a_{F}$ decreases $M_{F}$. That is, the income effect of $a_{F}$ on $M_{F}$ dominates its substitution effect.

${ }^{11} \mathrm{Neal}$ (2006) documents the fact that significant improvements in school quality for blacks during the 1970s and 1980s in the U.S. decreased the gap in black-white skills, as measured by test scores among U.S. youth during that period. However, he also shows that this skill gap increased again during the 1990s, suggesting the possibility of persistent barriers to skill development among more recent cohorts of black youth. Since the NLSY79 samples individuals born between 1957 and 1964, we explore the determinants of the black-white skill gap for those earlier cohorts, not the more recent cohorts.
} 
is the same across generations. In particular, costs to the three family types of investing in cognitive skills $(T)$ are defined by the following relation:

$$
a_{F}^{B 1}=a_{F}^{B 2} \geq a_{S}^{B 1}>a_{S}^{B 2}=a_{F}^{W}=a_{S}^{W},
$$

where the superscripts indicate the three family types: $B 1, B 2$, and $W$. We then assume that for returns to cognitive skills $(T)$ in Equation (5),

$$
\delta<1 / 2 \text {. }
$$

This assumption indicates that returns to cognitive skills $(T)$ are greater in the son's generation, which accords with the rise in returns to cognitive skills that occurred during the 1980s (see Murnane, Willett, and Levy, 1995; Katz and Autor, 1999; Ingram and Neumann, 2006; Bacolod and Blum, 2010; among others). ${ }^{12}$

Finally, we assume that the degree of skill inheritance $x$ has the same distribution for all family types.

We now present three predictions, which will be examined in the empirical sections 4 and 5:

\section{A comparison between sons within white families}

The cost of investing in $T$ skills is the same for father and son, but $x$ varies for each father-son pair. Thus, only P1 applies, and there will be a positive relation between the father-son skill correlation and the son's wages within white families. As a result, white sons who work in jobs requiring skills similar to those of their fathers earn higher wages than those who do not.

\section{A comparison between sons of B1 and B2 black families}

Equations (8) and (9) imply that $a_{S}^{I} /(1-\delta)<a_{F}^{I} / \delta$ where $I=\mathrm{B} 1$ and B2. Therefore, by $\mathrm{P} 2$,

$$
E\left[\cos \theta^{B 1}\right]>E\left[\cos \theta^{B 2}\right] \text { and } E\left[\omega_{S}^{B 1}\right]<E\left[\omega_{S}^{B 2}\right]
$$

where the operator $E[\cdot]$ indicates the conditional mean of each type (indicated by a superscript). A son in a B1 family, who pays a cost just as high as his father did to invest in $T$ skills, works in an occupation similar to his father's; however, this son

\footnotetext{
${ }^{12}$ Bacolod and Blum (2010), for example, find that the returns to working in occupations that require cognitive skills increased fourfold, based on the 1968-1990 Current Population Survey.
} 
receives lower wages when compared to a son in a B2 family, who pays less than his father to acquire $T$ skills. Thus, between B1 and B2 families, there is a negative relation between the father-son skill correlation and the son's wages. ${ }^{13}$

\section{A comparison between sons of white families and B2 black families}

Sons in B2 black families and in white families pay the same cost to invest in $T$ skills $\left(a_{S}^{B 2}=a_{S}^{W}\right)$, but B2 black fathers pay a higher cost to invest in $T$ skills than do white fathers $\left(a_{F}^{B 2}>a_{F}^{W}\right)$. Comparing these two family types enables us to study the effects of the insufficient investment in cognitive skills for black fathers on the earnings of the later generation. By $\mathrm{P} 3$, since $a_{S}^{I} /(1-\delta)<a_{F}^{I} / \delta$, where $I=\mathrm{B} 2$ and $\mathrm{W}$,

$$
E\left[\cos \theta^{B 2}\right]<E\left[\cos \theta^{W}\right] \text { and } E\left[\omega_{S}^{B 2}\right] \leq E\left[\omega_{S}^{W}\right]
$$

where the equality holds if $x$ is equal to zero. Compared to white sons, black sons in B2-type families work in occupations requiring skill combinations that differ from those of their fathers, and they earn lower wages. This wage gap between B2-type black sons and white sons is attributable to the difference in skills obtained by their fathers, because the costs to acquire skills are the same for both sets of sons $\left(a_{S}^{B 2}=a_{S}^{W}\right)$. Neal (2006) shows that the black-white difference in the fathers' cost of investing in cognitive skills influences their sons' human capital gap and thus their wage gap. Our explanation follows his argument. However, as P4 implies, when there is skill complementarity, the black-white difference in the father's costs of investing in cognitive skills widens the black-white gap in the son's attainment of both cognitive and other complementary skills, resulting in further widening of the black-white wage gap.

From Equations (10) and (11), the B1 black son receives the lowest wage, the B2 black son the second lowest, and the white son the highest $\left(E\left[\omega_{S}^{B 1}\right]<E\left[\omega_{S}^{B 2}\right] \leq E\left[\omega_{S}^{W}\right]\right)$. That is, wages of black sons are lower than those of white sons. Skill correlations between father and son are greater for both white and B1 black families than for B2 black families; however, the

\footnotetext{
${ }^{13} \mathrm{P} 2$ and Equations (8) and (9) imply that for any given $x \in[0,1], \cos \theta^{B 1}>\cos \theta^{B 2}$ and $\omega_{S}^{B 1}<\omega_{S}^{B 2}$ because $a_{S}$ varies. On the other hand, by reasoning similar to the first prediction for white families, there will be a positive relation within each black family type (B1 or B2) between the father-son skill correlation and the son's wages because $x$ varies. Therefore, within black families comprising B1 and B2 families, there will be a negative (positive) relation between the father-son skill correlation and the son's wages, if the variations in $\cos \theta$ and $\omega_{S}$ are greater (smaller) across B1 and B2 families than within each black family type. Details are available from the authors upon request. We will examine which relation holds for black families in the empirical sections 4 and 5 .
} 
relative magnitudes of the skill correlations are indeterminate between white and B1 black families $\left(E\left[\cos \theta^{W}\right]>E\left[\cos \theta^{B 2}\right]\right.$ and $\left.E\left[\cos \theta^{B 1}\right]>E\left[\cos \theta^{B 2}\right]\right)$.

In the empirical sections that follow, the skill components will be represented by 39 occupational characteristics from the Dictionary of Occupational Titles (DOT). We thus expand the number of skill components from two to $N(=39)$. The father's skill vector is expressed as

$$
\Psi_{F}=\left(\psi_{F}^{1}, \psi_{F}^{2}, \ldots, \psi_{F}^{N}\right)
$$

where $\psi_{F}^{1}, \psi_{F}^{2}, \ldots, \psi_{F}^{N}$ are the father's skill components. Similarly, the son's skill vector is expressed as

$$
\Psi_{S}=\left(\psi_{S}^{1}, \psi_{S}^{2}, \ldots, \psi_{S}^{N}\right)
$$

where $\psi_{S}^{1}, \psi_{S}^{2}, \ldots, \psi_{S}^{N}$ are the son's skill components. The model uses the cosine of the angle $\theta$ between the two skill vectors $\Psi_{F}$ and $\Psi_{S}$, which measures the closeness of the direction of the two skill vectors. ${ }^{14}$ However, in the empirical analysis below, we compute the correlation coefficient between the two vectors because it is a more widely used statistic for assessing correlations. $^{15}$

\footnotetext{
${ }^{14}$ Several occupational-distance measures have been developed to identify transferability of skills across occupations. Shaw $(1984,1987)$ measured the distance between two occupations by the frequency with which workers switch between the two occupations. A high probability of such movement implies greater similarity in occupational skills. More recently, Poletaev and Robinson (2008) used a distance measure based on the factor-score change to define similar occupations. Like our study, Gathmann and Schönberg (2010) use a measure of one minus the cosine.

${ }^{15}$ The cosine of the angle $\theta$ between $\Psi_{F}$ and $\Psi_{S}$ is defined as

$$
\cos \theta=\frac{\Psi_{F} \cdot \Psi_{S}}{\left\|\Psi_{F}\right\|\left\|\Psi_{S}\right\|}=\frac{\sum_{n=1}^{N} \psi_{F}^{n} \psi_{S}^{n}}{\sqrt{\sum_{n=1}^{N}\left(\psi_{F}^{n}\right)^{2}} \sqrt{\sum_{n=1}^{N}\left(\psi_{S}^{n}\right)^{2}}} .
$$

On the other hand, the correlation coefficient between between $\Psi_{F}$ and $\Psi_{S}$ is defined as

$$
r=\frac{\sum_{n=1}^{N}\left(\psi_{F}^{n}-\frac{1}{N} \sum_{n=1}^{N} \psi_{F}^{n}\right)\left(\psi_{S}^{n}-\frac{1}{N} \sum_{n=1}^{N} \psi_{S}^{n}\right)}{\sqrt{\sum_{n=1}^{N}\left(\psi_{F}^{n}-\frac{1}{N} \sum_{n=1}^{N} \psi_{F}^{n}\right)^{2}} \sqrt{\sum_{n=1}^{N}\left(\psi_{S}^{n}-\frac{1}{N} \sum_{n=1}^{N} \psi_{S}^{n}\right)^{2}}} .
$$

Wonnacott and Wonnacott (1979) explain that the correlation coefficient between the two vectors is identical to the cosine, except that the former uses the deviation from the mean.
} 


\section{Data and Descriptive Statistics}

\subsection{Dictionary of Occupational Titles (DOT)}

We draw on information about occupational characteristics from the fourth edition (1977) and revised fourth edition (1991) of the U.S. Department of Labor's Dictionary of Occupational Titles (DOT). Using guidelines supplied by the Handbook for Analyzing Jobs, the Department of Labor examiners evaluated more than 12,000 occupations along objective and subjective dimensions, including work functions, general educational development, worker aptitudes, temperaments, interests, physical strength, and environmental conditions. ${ }^{16}$ The DOT characteristics represent not only skills related to education (e.g., reasoning ability, mathematical ability, and language development), but also skills related to individuals' personality traits (e.g., adaptability to dealing with people and preference for activities involving business contacts with people) and to their motor aptitude (e.g., ability to perceive forms and spaces). The data in the fourth edition of the DOT (1977) were collected between 1966 and 1976, while those in the revised fourth edition of the DOT (1991) were collected between 1978 and 1990. The 1977 DOT skill measures therefore describe occupations in the 1970s (which overlap with fathers' occupations in our study), while the 1991 measures describe occupations in the 1980s (overlapping with the sons' occupations). ${ }^{17}$ All DOT variables are standardized to have a mean of 0 and a standard deviation of 1 in the 1971 CPS distribution. The textual definitions of DOT variables are used to identify four broad skill categories: cognitive skills, people skills, motor skills, and physical strength. ${ }^{18}$ The DOT variables are described in detail in Appendix

\footnotetext{
${ }^{16}$ The DOT has been used for job-matching applications, occupational and career guidance, employment counseling, and labor-market information services.

${ }^{17}$ Since DOT job codes are more detailed than census occupational codes, they are mapped to the 1970 census occupational codes at the three-digit level. Following Autor, Levy, and Murnane (2003), we use the April 1971 Current Population Survey issued by the National Academy of Sciences (1981), in which experts assign individual DOT job codes to each of the 60,441 workers in the sample. The DOT measures are rescaled so that higher values denote higher requirements, and are transformed into percentile values corresponding to their ranks in the 1971 distribution of skill input. Then, they are standardized to a mean of 0 and a standard deviation of 1 . The 1971 CPS sampling weights are used to calculate the means of each DOT characteristic by occupation and gender. In cases where an occupation cell exclusively contains men or women, the cell mean is assigned to both genders. To verify that our results are robust to plausible alternative selections of the DOT variables, we use raw DOT scores in a separate analysis, results of which are qualitatively identical.

${ }^{18}$ These skill classifications are also used by Bacolod and Blum (2010), who analyze changes in skill requirements and skill returns in the U.S. On the other hand, Ingram and Neumann (2006) use a factor analysis on the DOT data from the revised fourth edition (1991) to identify a parsimonious set of dimensions: intelligence, fine motor skill, coordination, and strength (which is negatively related to people skills). We also implement a factor analysis to corroborate our choice of skill categories. Most of our skill categorizations are consistent with the grouping from the factor analysis.
} 
Table 1.

\subsection{National Longitudinal Survey of Youth 1979 (NLSY79)}

This survey is sponsored by the Bureau of Labor Statistics of the U.S. Department of Labor, which gathers information at multiple points in time on individuals who were aged between 14 and 22 in 1979 when they were first surveyed. In addition to its cross-sectional sample, we include respondents from the supplemental sample of blacks but do not include those from the supplemental samples of Hispanics, economically disadvantaged whites, or military personnel. This procedure ensures that our samples are representative of both black and white populations. ${ }^{19}$

To obtain skill measures for NLSY79 fathers, we match fathers' occupations at the threedigit level when the sons (respondents) were aged 14 to the fourth edition of the DOT and let DOT skills stand for the fathers' skills. ${ }^{20}$ For sons, a match of occupation is incorporated in both the fourth edition (1977) and the revised fourth edition (1991), but the results are similar in the two editions. Therefore, we report those from the fourth edition of the DOT $(1977) \cdot{ }^{21}$

Following studies by Neal and Johnson (1996) and Neal (2006), we use the Armed Forces Qualification Test (AFQT) as a measure of cognitive skills for sons (respondents). The AFQT, a battery of tests of basic numeracy and literacy, is used by the military for enlistment,

\footnotetext{
${ }^{19}$ To construct indicators for white and black, we follow Neal $(2004,2006)$, who constructed the white indicator to match the census definition of white. Thus, respondents who report being Asian are excluded in the sample. Also, our sample includes sons from all birth years, as in Neal (2006).

${ }^{20}$ In 1979, the respondents were asked two questions regarding their father's occupation: (1) father's occupation when the respondent was age 14 and (2) father's occupation in the job he held the longest in 1978. The information on father's occupation when the respondent was age 14 is a more appropriate measure in our study, because the fathers presumably have a greater influence on the child's development (and skill acquisition) when the child is younger (age 14) than when the child is older (in 1978). Therefore, in constructing the father's occupation variable, we use the father's occupation when the respondent was age 14; but if this information is missing, we use the father's occupation in 1978. We obtain similar results when we do the other way around: i.e., when we use the father's occupation in 1979, and if this information is missing, we use the father's occupation when the respondent was age 14. For the respondent's occupation, we use his occupation at the current/most recent job held since the last interview (CPS job). If the respondents worked for more than one employer (i.e., held multiple occupations), the CPS jobs are the jobs at which they report working the most hours during the last week (or the jobs at which they worked most recently).

${ }^{21}$ We assume that the workers hold occupations that match their traits and personalities. This assumption corresponds to the assignment model of interpersonal interaction developed by Borghans, ter Weel, and Weinberg (2008). Their model indicates that a worker's behavior is determined by job circumstances and the worker's personality, and that a worker with a comparative advantage in a certain behavior will be assigned to the job which demands that behavior more. They empirically test and confirm these model implications. Alternatively, Borghans, ter Weel, and Weinberg (2014) and Okumura and Usui (2014) find that self-reported sociability measures have a large and positive association with their people-task measures from the DOT.
} 
screening, and job assignments. It was administered to almost the entire NLSY79 sample. Wigdor and Green (1991) find that the AFQT does not underpredict military job performance for blacks and is not otherwise biased with respect to blacks or whites. Test scores have been age-standardized, such that they have a mean of 0 and a standard deviation of 1 .

\subsection{Descriptive Statistics}

We provide facts regarding the differences in the black-white skill gap between fathers and sons in the NLSY79 sample. Table 1 presents means and standard deviations of demographic characteristics and occupational skills of fathers and sons. We have information about fathers at one point in time, but for sons we have multiple-year observations, and we report the means and standard deviations for the 1993 and 2000 waves. $^{22}$ In the 1993 wave, sons (i.e., NLSY79 respondents) were aged between 28 and 36, and, on average, 11 years younger than their fathers were when the information on the latter's occupations was available. Education levels are: 12.5 years for white fathers, 10.4 for black fathers, 13.5 for white sons, and 12.6 for black sons. There is a greater increase in education level across the two generations for blacks than for whites, although black sons' education level remains lower than that of white sons. $^{23}$

The DOT cognitive- and people-skill variables increase between the 1993 and 2000 waves for both white and black sons. For white sons in the 2000 wave, the variables are slightly higher than those for their fathers, but this is not the case in the 1993 wave. For black sons, the variables are higher in both waves, and in the 2000 wave are about 0.2 points higher than those for their fathers. The increase in these DOT skills for blacks parallels their growth in education levels. However, just as white sons continue to have, on average, a higher educational level than black sons, white sons in the 2000 wave continue to have higher DOT scores for both cognitive and people skills than black sons.

\footnotetext{
${ }^{22}$ In the 1993 wave, the response rate excluding the deceased is the highest after the 1990 wave. The 2000 wave is the last year in which the respondent's occupation is coded with the three-digit 1970 census occupation codes. As reported in Table 1, the sample size is 1,854 for white fathers and 715 for black fathers; here, we use fathers for whom we have valid information on their education and occupation, and whose sons were interviewed in the 1993 wave. The sample size is 1,752 for white sons and 601 for black sons in the 1993 wave; here, we use sons for whom we have valid information on fathers' education and occupation and who themselves reported valid information on their education and occupation.

${ }^{23}$ Similarly, relative to whites, the proportion of blacks who work in professional or managerial occupations increases from fathers to sons. The percentage of whites working for pay is 95.2 percent for fathers and 97.1 percent for sons, while the percentage of blacks working for pay is lower: 90.0 percent for fathers and 90.3 percent for sons.
} 
Most of the DOT motor-skill variables and all of the DOT physical-strength variables decline from fathers to sons for both whites and blacks. This decline is greater for blacks than whites; in particular, the decrease in "manual dexterity" and "strength" is especially large for blacks. Although the black-white gaps in the DOT physical-strength variables narrow from fathers to sons, these scores remain higher for blacks than for whites in the 2000 wave.

In summary, black-white skill gaps narrowed between fathers and sons in the NLSY79 sample, but significant black-white skill gaps remain among sons.

\section{Skill Correlation between Father and Son}

We begin this section by showing that each of the DOT skills is related between father and son for both whites and blacks. We then study differences between blacks and whites in the overall skill correlation by computing the correlation coefficient between the father's and the son's skill vectors.

\subsection{Correlation by Each Skill Component}

In Table 2, we display the correlation matrix of father-son skills separately for whites and blacks, with information for sons taken from the 1993 wave. The on- and off-diagonal correlations are large and positive within the categories of cognitive and people skills. The on-diagonal correlations within the category of motor skills are somewhat large and positive, but the off-diagonal correlations are smaller and take both positive and negative values. Most correlations between father and son are greater for whites than for blacks.

Table 3 presents estimates of the effect of fathers' DOT skill variables on the corresponding DOT skill variables of the sons, using the sons' sample between 1990 and 2000 (separately for blacks and whites). The regressions include sons' education, a quadratic in sons' AFQT score, a cubic in sons' labor-market experience, sons' place of residence, fathers' education, a dummy for whether father and son work in the same occupation, and year dummies. Most of the DOT skill variables (including cognitive, people, and motor skills and physical strength) for white fathers have a large positive and significant relationship with the corresponding DOT skill variables of the white sons. Black fathers' motor-skill variables have a positive and significant relationship with the corresponding motor-skill variables for black sons. The magnitudes of these associations are about the same as those of the associations of white fathers' motor-skill variables with those for white sons. Although several cognitive-skill and 
people-skill variables for black fathers have a positive and significant association with the black sons, all the physical-strength variables for black fathers have a small and insignificant association with the black sons. We then include a term that interacts the father's DOT skill variable with the son's labor-market experience in the regression model, using the sons' sample between 1979 and 2000. The coefficients for this term are positive for most DOT skill variables for white father-son pairs, but are positive only for a few black father-son pairs (not reported). This indicates that sons' occupational skills draw closer to their fathers' skills over time for whites but not for blacks.

In sum, each of the fathers' skill sets is positively linked to the sons' corresponding skill set, but the link is stronger for whites than for blacks.

\subsection{Overall Skill Correlation}

To measure skill correlation between father and son, Table 4 reports the mean and standard deviation of the correlation coefficient of the father's and the son's skill vectors. The individual's skill vector is composed of the DOT skill variables listed in Appendix Table 1, and Table 4 presents the correlation coefficient for using all the DOT skills (39 variables). ${ }^{24}$ Data for sons are taken from the 1993 and 2000 waves (reported separately by year and race).

For white fathers and sons in the 1993 wave, skill correlation rises as fathers' education increases, from 0.153 for fathers with high-school education to 0.265 for fathers with college education. In the 2000 wave, the skill correlations for fathers with high-school education and college education increase to 0.169 and to 0.331 , respectively. ${ }^{25}$

In the 1993 wave, 5.3 percent of white fathers and sons work in the same occupation, and these pairs raise the correlation coefficients because their correlation coefficients are one. When we exclude these father-son pairs, the correlation coefficient drops by 0.046; the correlation coefficient then ranges between 0.102 and 0.234 and continues to increase with the father's education level. Skill correlation remains even when father-son pairs who work in the same occupation have been excluded.

\footnotetext{
${ }^{24}$ In an alternative analysis, by assuming that a subset of DOT variables measures a single skill, we construct a cognitive-skill index that is derived from the first component of the principal component analysis on DOT cognitive skills (for textual definitions, see Appendix Table 1). Likewise, we construct a people-skill index, a motor-skill index, and a physical-strength index. We then compute the correlation coefficient of these indices between father and son. The results using this measure are similar to those presented in this paper.

${ }^{25}$ Note that the proportion of white sons who work in the same occupation as their fathers also increases from 5.3 percent in 1993 to 6.6 percent in 2000, whereas for black sons, the corresponding numbers are 3.0 percent in 1993 and 3.4 percent in 2000.
} 
For black fathers and sons in the 1993 wave, skill correlation is 0.297 for fathers with less-than-high-school education, 0.143 for those with a high-school education, 0.019 for those with some college education, and 0.252 for those with college education. Sons of the least educated (less-than-high-school) and the most highly educated (college-educated) black fathers work in occupations similar to their fathers' ${ }^{26}$ In general, there is a greater skill correlation within those white and black families with highly educated fathers. There is also a skill correlation for black families with the least-educated fathers. Between the 1993 and 2000 waves, skill correlation within white families has increased, but skill correlation for black families has declined; in particular, skill correlation for black families with fathers with high-school education is reduced from 0.143 in the 1993 wave to 0.059 in the 2000 wave.

To get a better understanding of skill correlation between father and son, the cumulative distribution functions (c.d.f.) of the correlation coefficient between father and son for whites in the 1993 wave are shown in Figure 2, Panel A and for blacks in Figure 2, Panel B. The c.d.f. distribution, represented by the solid line, is skewed toward the left for both whites and blacks, suggesting positive skill correlations. ${ }^{27}$

Even if individuals are randomly assigned to different skill combinations, however, skill correlation may occur, especially if the skill sets available to them are limited. To consider this, we compute skill correlations that will be observed under random allocation. Specifically, we construct hypothetical father-son pairs by matching fathers and sons randomly from the pool of the NLSY79 father-son sample (but keeping blacks and whites separate), and then we compute the correlation coefficients between these father and son. We repeat these simulations a hundred times and take the average of the generated correlation coefficients. The c.d.f. distribution of the correlation coefficient for these randomly matched father-son pairs is represented by the dotted line in Figure 2, Panel A for whites and in Figure 2, Panel B for blacks. The median of the distribution of the correlation coefficient for the randomly matched father-son pairs is 0.011 for whites but 0.199 for blacks; this implies a positive skill correlation even under random matching of fathers and sons for blacks but not for whites. The differences between the actual father-son pairs (solid line) and the randomly matched father-son pairs (dotted line) represent skill correlations that go beyond those that occur under random matching of fathers and sons. Figure 2, Panel C plots this difference by the percentile of

\footnotetext{
${ }^{26}$ The correlation coefficient remains high for these groups in the 2000 wave: 0.228 for fathers with lessthan-high-school education and 0.267 for those with college education.

${ }^{27}$ The median of the distribution of the correlation coefficient is 0.252 for whites and 0.258 for blacks, while the mean is 0.193 for whites and 0.219 for blacks.
} 
the c.d.f. distribution (separately for whites and blacks). Relative to the distribution of the randomly matched father-son pairs, the actual distribution is skewed more toward the left, and the skewness is greater for whites than for blacks. We therefore find a large positive correlation between the skills of actual father-son pairs for whites. In contrast, for blacks, the actual distribution of correlation coefficients makes a rather small parallel rightward shift from the correlations generated by random matching; this implies that skill sets available to black fathers and sons are limited, and that the correlations of skills across generations for blacks are closer to a random matching.

\section{Economic Returns to Father-Son Skill Correlation}

The theoretical analysis of Laband and Lentz (1983) offers two reasons for occupational following. First, sons inherit name-brand loyalty capital from their fathers, where value is maximized when sons work in the same occupation as their fathers, the so-called "nepotism." Second, sons receive a direct transfer of career-related human capital by way of informal "onthe-job training" from their fathers. Lentz and Laband (1989) and Laband and Lentz (1992) test evidence for nepotism versus transfer of career-related human capital in two professions, those of doctors and lawyers. In their 1989 paper, they found evidence of the transmission of career-related human capital for lawyers, because lawyers' sons who follow in their parents' occupational footsteps receive an earning premium only if their parents talk about their careers with them. In contrast, in their 1992 paper, they found evidence of nepotism among doctors.

The model in Section 2 predicts that skills transfer not only from fathers to sons who work in their fathers' occupations but also to sons who work in occupations requiring skills similar to those of their fathers. Specifically, skill transfer $(x)$ enables sons to hold more skills and earn higher wages; sons therefore benefit from working in positions that require skills similar to those of their fathers (see P1). However, from the analysis on the effects of the fathers' and sons' costs of investing in cognitive skills $\left(a_{F}\right.$ and $\left.a_{S}\right)$ on the sons' wages, the model also predicts that sons earn lower wages when they work in occupations that require skills similar to those of their fathers, for whom the costs of investing in cognitive skills were higher (see P2 and P3). As the model predicts an opposite relationship between the sons' wages and the father-son skill correlation, we now examine which effect is more dominant for whites and blacks. 
Using the NLSY79 sample, we identify the wage effects of both nepotism and the transfer of skill-related human capital by including (1) a dummy for whether father and son work in the same occupation, and (2) the correlation coefficient between father-son skill vectors as regressors in the wage regression model posited by Neal and Johnson (1996). Consider the following wage regression:

$$
w_{S}=\alpha_{0} B+\alpha_{1} W \times r+\alpha_{2} B \times r+\alpha_{3} W \times \mathbf{1}_{o c c}+\alpha_{4} B \times \mathbf{1}_{o c c}+X \Gamma+\varepsilon,
$$

where $w_{S}$ is the log of the son's wage; $B$ is an indicator for black; $W$ is an indicator for white; $r$ is the correlation coefficient between father-son skill vectors; $\mathbf{1}_{o c c}$ is an indicator of whether the son and the father work in the same occupation; $X$ includes controls for the son's AFQT score and its square, son's age, father's education, and father's DOT skill variables; $\varepsilon$ is an error term; and $\alpha_{0}, \alpha_{1}, \alpha_{2}, \alpha_{3}, \alpha_{4}$, and $\Gamma$ represent the coefficients of the respective variables in the wage regression. We include the father's DOT skill variables in the wage regression to control for the father's skill vectors. ${ }^{28}$

In the above wage regression, the coefficients $\alpha_{1}$ and $\alpha_{2}$ reflect the returns to working in occupations that require skills similar to those of the fathers for white and black sons, respectively. When the coefficients are positive, the sons receive a pay premium for working in jobs that require skills similar to their fathers', but when the coefficients are negative, the sons incur a wage penalty. On the other hand, the coefficients $\alpha_{3}$ and $\alpha_{4}$ reflect the nepotism effect, which measures the wage premium that white and black sons, respectively, receive from working in the same occupation as their fathers.

Table 5 reports the mean regression estimates of Equation (12) for the 1993, 1996, 1998, and 2000 waves, separately. In the 1993 wave, the coefficient on skill correlation for whites $\alpha_{1}$ is 0.080 (0.026), while that coefficient for blacks $\alpha_{2}$ is $-0.102(0.045)$, with both being significant at the 5 percent level (Table 5, Column (3)). White sons thus earn higher wages when they work in jobs similar to those of their fathers. However, black sons earn less when they work in jobs similar to those of their fathers. In other words, white sons receive a wage premium resulting from the positive skill transfer from their fathers, while black sons receive lower wages because the effect of their fathers' limited skill acquisition dominates the effect of positive skill transfer. ${ }^{29}$ There is weak evidence for nepotism, as the coefficient on nepotism

\footnotetext{
${ }^{28}$ All wages are measured in 1990 dollars. The observations in which the wage is below $\$ 2$ or above $\$ 100$ in 1990 dollars are eliminated from the analysis.

${ }^{29}$ We examine whether the effects of skill correlation on wages differ depending on the father's occupation (white-collar, blue-collar, and other, as defined in Bjerk (2007)). The coefficient on skill correlation is 0.009
} 
for whites $\alpha_{3}$ is $0.146(0.062)$ and that coefficient for blacks $\alpha_{4}$ is 0.095 (0.124), which are both positive, but significant at the 5 percent level only for whites.

In the specification of the mean regression without the skill correlation terms, the coefficient on black $\alpha_{0}$ is -0.051 (0.027) for the 1993 wave (Table 5, Column (2)), which is negative and significant. In contrast, the specification that includes the skill correlation terms takes a coefficient $\alpha_{0}$ of -0.015 (0.029) (Table 5, Column (3)), which is small in magnitude and insignificant. This result indicates that skill transfer from fathers to sons explains nearly 70 percent of the black-white wage gap, after controlling for cognitive skills. Although much of the black-white wage gap is explained by differences in cognitive skills among sons, as Neal and Johnson (1996) found, ${ }^{30}$ a significant portion of the remaining black-white wage gap is attributable to the differences in the wage premium earned by white sons and the wage penalty paid by black sons for working in occupations that require skills similar to their fathers' ${ }^{31}$

For the mean regression estimates of Equation (12) for the 1996 and 1998 waves (Table 5, Columns (4) and (5), respectively), we find similar results to those for the 1993 wave (Table 5, Column (3)). Specifically, the coefficient on black $\alpha_{0}$ is negative but small in magnitude and insignificant, whereas the coefficient on skill correlation for blacks $\alpha_{2}$ is significantly negative and as large as that of the 1993 wave: -0.113 (0.049) in the 1996 wave and -0.109 (0.045) in the 1998 wave. However, for the 2000 wave (Table 5, Column (6)), the coefficient on black $\alpha_{0}$ is -0.052 (0.030), which is significant and large in magnitude; and the coefficient on skill correlation for blacks $\alpha_{2}$ is -0.038 (0.047), which is insignificant and small in magnitude. Therefore, the explanation for the black-white wage gap may differ between pre-1998 and

(0.035) for whites whose fathers work in the blue-collar sector and $-0.165(0.049)$ for blacks whose fathers work in the blue-collar sector. However, the coefficient on skill correlation is positive for sons whose fathers work in the white-collar sector, regardless of race: specifically, 0.195 (0.041) for whites and 0.339 (0.133) for blacks. Since the proportion of blacks whose fathers work in the white-collar sector is only 8.6 percent, while it is 34.5 percent for whites, the overall skill-correlation effect is negative for blacks, as shown in Table 5, Column (3). We further examine the effects of skill correlation on wages for fathers with a higher school education or less. The results that restrict the sample to fathers with a high school education or less are similar to those that use all the fathers (Table 5, Column (3) and Figure 3), except for the coefficient estimate on White $\times r$. Specifically, the OLS estimate is $0.023(0.032)$ for the sample that restricts fathers to those with a high school education or less, while it is larger and $0.080(0.026)$ for the sample that uses all the fathers. This result implies that white sons whose fathers have a lower education level receive a smaller positive skill transfer from their fathers.

${ }^{30}$ We confirm this finding of Neal and Johnson (1996) by using our sample; the coefficient on black is -0.091 (0.026) for the case in which the sons' AFQT score is included in the mean regression (Table 5, Column (1)), while it is $-0.313(0.025)$ for the case where it is not included.

${ }^{31}$ The reduction in the black-white wage gap, which results from including the correlation coefficient in the wage regression, is approximately equal to the difference between $\alpha_{1}=0.080$ and $\alpha_{2}=-0.102$, multiplied by the average correlation coefficient (around 0.2). 
2000, a point which we discuss further later in this section.

Figure 3 presents a visual summary of the quantile regression results for the 1993 wave, which illustrates how changes in skill transfer are related to the changes in wages not only in the middle of the wage distribution but also in its tails. This method is useful because disadvantaged blacks are typically overrepresented in the lower tail of the wage distribution, and so we examine whether there are differential effects among blacks. For each of the coefficients on $\alpha_{0}, \alpha_{1}, \alpha_{2}, \alpha_{3}$, and $\alpha_{4}$, we plot the 19 distinct quantile regression estimates for each quantile, ranging from 0.05 to 0.95 as the solid curve. The shaded grey area represents a 90 percent confidence interval for the quantile regression estimates. The dashed line in each figure shows the OLS estimate, and the two light dotted lines represent the 90 percent confidence interval for the OLS estimate. ${ }^{32}$

For whites, the coefficients on skill correlation $\alpha_{1}$ are significantly positive and largest at the lower tail of the wage distribution, and continue to be significantly positive until the 55th quantile of the wage distribution but thereafter become smaller and less significant (Figure 3, Panel B). Meanwhile, for whites, the nepotism effects $\alpha_{3}$ are positive, and become larger and more significant toward the upper tail of the wage distribution (Figure 3, Panel D).

On the other hand, for blacks, the coefficients on skill correlation $\alpha_{2}$ are negative throughout the entire wage distribution (Figure 3, Panel C). In particular, between the 40th and 80th quantiles of the wage distribution, the coefficients on skill correlation for blacks $\alpha_{2}$ are significantly negative, while the coefficients on black $\alpha_{0}$ are significantly negative at the lower tail of the wage distribution - specifically, in the 10th and 20th quantiles of the wage distribution (Figure 3, Panel A). ${ }^{33}$ It follows that the black-white wage gap in the middle of the wage distribution arises from the differences in the effects of skill transfer from fathers, whereas the wage gap in the lower tail of the wage distribution arises from other, unexplained black-white differences not controlled for in the wage regression. ${ }^{34}$ These results indicate that blacks in

\footnotetext{
${ }^{32}$ In the lowest tenth percentile of the wage distribution, 57.7 percent are blacks, while in the highest tenth percentile of the wage distribution, 15.4 percent are blacks. Therefore, whites are sufficiently represented in the lowest tenth percentile of the wage distribution and blacks in the highest tenth percentile of the wage distribution.

${ }^{33}$ Using a semi-parametric procedure developed by DiNardo, Fortin, and Lemieux (1996) for estimating counterfactual distributions, O'Neill, Sweetman, and Van de gaer (2006) specify the wage model as in Neal and Johnson (1996), and find that differences in cognitive skills cannot fully explain the black-white wage gap at the lower end of the wage distribution.

${ }^{34}$ We obtain similar qualitative results for the quantile regressions when other waves between 1990 and 2000 are used; specifically, the coefficients on skill correlation for whites $\alpha_{1}$ are positive at the lower tail of the wage distribution, the coefficients on skill correlation for blacks $\alpha_{2}$ are negative at the middle of the wage distribution, and the coefficients on black $\alpha_{0}$ are negative at the lower tail of the wage distribution. We show
} 
the lower tail of the wage distribution are hampered in achieving economic success because of unexplained difficulties (such as discrimination), while blacks in the middle of the wage distribution are hampered because of the negative effect of skill transfer from their fathers.

The model in Section 2 provides an explanation for these empirical findings. Black fathers in both B1 and B2 families paid a greater cost to invest in cognitive skills ( $T$ skills) than white fathers. Because of the difficulty that blacks experienced in accessing quality schools before the Supreme Court's decision in Brown v. Board of Education in 1954 and the civil rights legislation of the mid-1960s, the black fathers faced greater difficulty than white fathers in obtaining quality education and cognitive skills when they were young. Such costs have declined in the sons' generation for B2 families because those blacks had greater freedom in choosing their residential communities and schools. However, B1 black sons continue to pay costs as high as their fathers paid, because they continue to face the difficulty of obtaining quality education and developing cognitive skills (potentially due to discrimination). The model predicts that the B1 black sons work in jobs similar to those of their fathers and receive significantly low wages, whereas the B2 black sons work in different jobs and receive low wages compared to those of white sons (but not as low as the B1 black sons) $\left(E\left[\omega_{S}^{B 1}\right]<E\left[\omega_{S}^{B 2}\right] \leq E\left[\omega_{S}^{W}\right]\right)$. The B1 black sons therefore incur a wage loss because they have to choose skill sets from those as limited as their fathers. The B2 black sons pay a price when they seek higher wages, because they have to move away from their fathers' occupation in order to do so, a move which incurs the cost of acquiring different skill sets than those they may have inherited from their fathers. In contrast, white fathers and sons who both pay lower costs to invest in cognitive skills work in similar jobs and receive higher wages. White sons therefore receive a wage gain from the positive skill transfer from their fathers.

Lastly, we assess how the racial differences in skill correlation between father and son contribute to the racial wage gap of sons between 1993 and 2000. According to Table 4, from 1993 to 2000 the average skill correlation increased for whites from 0.191 to 0.210 , but decreased for blacks from 0.216 to 0.147. Meanwhile, for both blacks and whites, the coefficients on skill correlation in the 2000 wave, as shown in Table 5, Column (6), are smaller in magnitude than those in the 1993 wave. We therefore can see that the average skill

the quantile regression results for the 1993 wave because that wave provides the clearest results. Furthermore, to deal with multiple siblings in the NLSY, we estimate the OLS and quantile regressions by clustering the standard errors at the family level. The standard errors are similar to those reported in the paper. We also conduct robustness checks by restricting the sample to full-time/full-year employment, the results of which show patterns similar to the estimates in Table 5 and Figure 3. These results are all available from the authors upon request. 
correlation changed in the direction of improving the sons' economic outcomes for both whites and blacks, but the coefficient on skill correlation changed in the direction of benefiting blacks but not whites. Following Smith and Welch (1989), Heckman, Lyons, and Todd (2000), and Barr and Lin (2015), we decompose the change in the sons' black-white wage gap between 1993 and 2000 into the changes due to (i) changing characteristics, and (ii) changing returns to characteristics, and we do this in three steps. Step 1: Separately by race and year, we estimate the wage regression of Equation (12): $w_{S, t}^{I}=\gamma_{0}+\gamma_{1} r_{t}^{I}+\gamma_{2} \mathbf{1}_{o c c}^{I}+X_{t}^{I} \Gamma_{t}^{I}+\varepsilon_{t}^{I}$ for $I=B, W$ and $t=1993$, 2000. Step 2: We obtain $\bar{z}^{W}$ and $\bar{z}^{B}$, which respectively denote the mean vectors of the white and black characteristics included as independent variables in the wage regression; and $\gamma^{W}$ and $\gamma^{B}$ which respectively denote the associated vectors of the coefficients. Step 3: We decompose the change in log white wages minus log black wages between 1993 and $2000\left(=\left(\bar{w}_{2000}^{W}-\bar{w}_{2000}^{B}\right)-\left(\bar{w}_{1993}^{W}-\bar{w}_{1993}^{B}\right)=0.068\right)$ as:

$$
\begin{array}{rlr}
{\left[\left(\bar{z}_{2000}^{W} \gamma_{2000}^{W}-\bar{z}_{2000}^{B} \gamma_{2000}^{B}\right)-\left(\bar{z}_{1993}^{W} \gamma_{1993}^{W}-\bar{z}_{1993}^{B} \gamma_{1993}^{B}\right)\right]} & \\
=\left[\left(\bar{z}_{2000}^{W}-\bar{z}_{2000}^{B}\right)-\left(\bar{z}_{1993}^{W}-\bar{z}_{1993}^{B}\right)\right] \gamma_{1993}^{B} & \text { Main Effect } \\
\quad+\left(\bar{z}_{2000}^{W}-\bar{z}_{1993}^{W}\right)\left(\gamma_{1993}^{W}-\gamma_{1993}^{B}\right) & \text { Race Interaction Effect } \\
\quad+\left(\bar{z}_{2000}^{W}-\bar{z}_{2000}^{B}\right)\left(\gamma_{2000}^{B}-\gamma_{1993}^{B}\right) & \text { Year Interaction Effect } \\
+\bar{z}_{2000}^{W}\left[\left(\gamma_{2000}^{W}-\gamma_{2000}^{B}\right)-\left(\gamma_{1993}^{W}-\gamma_{1993}^{B}\right)\right] . & \text { Race-Year Interaction Effect. }
\end{array}
$$

The main effect measures the change in the wage gap predicted by the change in the characteristics of whites relative to blacks from 1993 to 2000, valued at 1993 black return values. The race-year interaction effect measures the change in the wage gap that occurs because the relative returns to characteristics of blacks and whites changed between 1993 and 2000, valued at 2000 white characteristic values.

Table 6, Panel C presents the detailed decomposition results only for the skill correlation $r$ and nepotism $\mathbf{1}_{o c c} \cdot{ }^{35}$ First, the main effect of skill correlation $r$ is negative but fairly small $(-0.007)$, and so it played a minor role in closing the wage gap. Second, the race-year interaction effect of skill correlation $r$ is -0.021 , and so the changes in the returns to skill correlation $r$ move in the direction of closing the black-white wage gap. Third, the race interaction effect and year interaction effect both take positive values but their effects are small (0.001 and 0.003, respectively). Therefore, although the skill correlation $r$ served to close the black-white wage gap between 1993 and 2000 (by -0.024), the overall change in the

\footnotetext{
${ }^{35}$ Results for the other variables are available from the authors upon request.
} 
racial log wage gap widened by 0.068 log points between 1993 and 2000, since the changes in other factors widened the racial wage gap. ${ }^{36}$

\section{Concluding Remarks}

This paper examines how fathers' occupational skills affect sons' occupational decisions and earnings. We present a model of intergenerational multidimensional-skill transmission that extends a model of univariate human capital into a model of multidimensional human capital. The vector of skill sets for an individual comprises his occupational characteristics from the Dictionary of Occupational Titles (DOT). The correlation coefficient of the father-son skill vectors measures the closeness of the direction of these vectors. Skill correlation is found for father-son pairs, and the correlation (which goes beyond random assignment) is greater for whites than for blacks.

White sons earn a wage premium for working in occupations that require skills similar to those of their fathers, whereas black sons in such circumstances incur a wage penalty. We also find evidence for nepotism when white sons earn a wage premium for working in the same occupation as their fathers.

Although black-white skill gaps significantly narrowed from fathers to sons in the NLSY79 sample, the skill and wage gaps have persisted between black and white sons. Black sons who have skill sets as limited as their fathers work in occupations that require skills similar to those of their fathers, and they earn significantly lower pay. Even black sons who can choose from a wider variety of skill sets than their fathers incur the cost of acquiring these skill sets, and they earn low pay. Because these black sons, unlike white sons, cannot fully benefit from positive skill transfer from their fathers, this results in a wage disparity between the black and white sons.

\footnotetext{
${ }^{36}$ Alternatively, we decomposed the change in the black-white sons' wage gap between 1993 and 1998. Although the magnitude of the change in the black-white sons' wage gap is only 0.036 between 1993 and 1998, we obtained the same conclusion, namely, that skill correlation worked in the direction of closing the black-white wage gap. Note, however, that the wage gap may arise from selective attribution and sample differences between the two waves. These results are available from the authors upon request.
} 


\section{References}

[1] Altonji, Joseph G., and Rebecca M. Blank. 1999. Race and Gender in the Labor Market. In Handbook of Labor Economics. Vol. 3C, ed. Orley Ashenfelter and David Card. Amsterdam: Elsevier Science.

[2] Autor, David H., Frank Levy, and Richard J. Murnane. 2003. The Skill Content of Recent Technological Change: An Empirical Exploration. Quarterly Journal of Economics 118, no. 4:1279-333.

[3] Bacolod, Marigee, and Bernardo S. Blum. 2010. Two Sides of the Same Coin: U.S. "Residual Inequality" and the Gender Gap. Journal of Human Resources 45, no. 1:197242.

[4] Barr, Tavis and Carl Lin. 2015. A Detailed Decomposition of Synthetic Cohort Analysis. Economics Letters 127, 76-80.

[5] Becker, Gary S., and Nigel Tomes. 1976. Child Endowments, and the Quantity and Quality of Children. Journal of Political Economy 84, no. 4:S143-S162.

[6] Bjerk, David. 2007. The Differing Nature of Black-White Wage Inequality Across Occupational Sectors. Journal of Human Resources 42, no. 2:398-434.

[7] Björklund, Anders, Mikael Lindahl, and Erik Plug. 2006. The Origins of Intergenerational Associations: Lessons from Swedish Adoption Data. Quarterly Journal of Economics 121, no. 3:999-1028.

[8] Borghans, Lex, Bas ter Weel, and Bruce A. Weinberg. 2008. Interpersonal Styles and Labor Market Outcomes. Journal of Human Resources 43, no. 4:815-58.

[9] Borghans, Lex, Bas ter Weel, and Bruce A. Weinberg. 2014. People People: Social Capital and the Labor Market Outcomes of Underrepresented Groups. Industrial and Labor Relations Review 67, no. 2:287-334.

[10] DiNardo, John, Nicole M. Fortin, and Thomas Lemieux. 1996. Labor Market Institutions and the Distribution of Wages 1973-1992: A Semi-Parametric Approach. Econometrics 64, no.5:1001-44. 
[11] Gathmann, Christina, and Uta Schönberg. 2010. How General Is Human Capital? A Task-Based Approach. Journal of Labor Economics 28, no. 1:1-49.

[12] Guryan, Jonathan. 2004. Desegregation and Black Dropout Rates. American Economic Review 94. no. 4:919-43.

[13] Heckman, James J., Thomas M. Lyons, and Petra E. Todd. 2000. Understanding BlackWhite Wage Differentials, 1960-1990. American Economic Review 90, no. 2:344-49.

[14] Hedges, Larry V., and Amy Nowell. 1998. Black-White Test Score Convergence Since 1965. In The Black-White Test Score Gap, ed. Christopher Jencks and Meredith Phillips. Washington, DC: Brookings Institution Press.

[15] Ingram, Beth F., and George R. Neumann. 2006. The Returns to Skill. Labour Economics 13, no. 1:35-59.

[16] Ishikawa, Tsuneo. 1975. Family Structures and Family Values in the Theory of Income Distribution. Journal of Political Economy 83, no. 5:987-1008.

[17] Johnson, Rucker C. 2014. Long-run Impacts of School Desegregation and School Quality on Adult Attainments. NBER Working Paper 16664.

[18] Katz, Lawrence, and David H. Autor. 1999. Changes in the Wage Structure and Earnings Inequality. In Handbook of Labor Economics. Vol. 3A, ed. Orley Ashenfelter and David Card. Amsterdam: Elsevier Science.

[19] Laband, David N., and Bernard F. Lentz. 1983. Like Father, Like Son: Toward an Economic Theory of Occupational Following. Southern Economic Journal 50, no. 2:474-93.

[20] Laband, David N., and Bernard F. Lentz. 1992. Self-Recruitment in the Legal Profession. Journal of Labor Economics 10, no. 2:182-201.

[21] Lentz, Bernard F., and David N. Laband. 1989. Why So Many Children of Doctors Become Doctors. Journal of Human Resources 24, no. 3:396-413.

[22] Murnane, Richard J., John B. Willett, and Frank Levy. 1995. The Growing Importance of Cognitive Skills in Wage Determination. Review of Economics and Statistics 77, no. 2:251-66. 
[23] National Academy of Science, Committee on Occupational Classification and Analysis. 1981. Fourth Edition Dictionary of DOT Scores for 1970 Census Categories. ICPSR Document No. 7845. Ann Arbor, MI.

[24] Neal, Derek A. 2004. The Measured Black-White Wage Gap among Women Is Too Small. Journal of Political Economy 112, no. 1:S1-S28.

[25] Neal, Derek A. 2006. Why Has Black-White Skill Convergence Stopped? In Handbook of Economics of Education, ed. Eric Hanushek and Finis Welch. Amsterdam: Elsevier Science.

[26] Neal, Derek A., and William R. Johnson. 1996. The Role of Pre-Market Factors in BlackWhite Wage Differences. Journal of Political Economy 104, no. 5:869-95.

[27] Okumura, Tsunao, and Emiko Usui. 2014. Do Parents' Social Skills Influence Their Children's Sociability? The B.E. Journal of Economic Analysis and Policy 14, no 3:1081116.

[28] O’Neill, Donal, Olive Sweetman, and Dirk Van de gaer. 2006. The Impact of Cognitive Skills on the Distribution of the Black-White Wage Gap. Labour Economics 14, no.3:34356.

[29] Poletaev, Maxim, and Chris Robinson. 2008. Human Capital Specificity: Evidence from the Dictionary of Occupational Titles and Displaced Worker Surveys, 1984-2000. Journal of Labor Economics 26, no. 3:387-420.

[30] Reber, Sarah J. 2010. School Desegregation and Educational Attainment for Blacks. Journal of Human Resources 45, no. 4:893-914.

[31] Sacerdote, Bruce. 2007. How Large Are The Effects From Changes In Family Environment? A Study of Korean American Adoptees. Quarterly Journal of Economics 121, no. $1: 119-58$.

[32] Shaw, Kathryn. 1984. A Formulation of the Earnings Function Using the Concept of Occupational Investment. Journal of Human Resources 19, no. 3:319-40.

[33] Shaw, Kathryn. 1987. Occupational Change, Employer Change and the Transferability of Skills. Southern Economic Journal 53, no. 3:702-19. 
[34] Smith, James P. and Finis R. Welch. 1989. Black Economic Progress after Myrdal. Journal of Economic Literature 27:519-564.

[35] U.S. Department of Labor, Employment and Training Administration. 1977. Dictionary of Occupational Titles: Fourth Edition. Washington, DC.

[36] U.S. Department of Labor, Employment and Training Administration. 1991. Dictionary of Occupational Titles: Revised Fourth Edition. Washington, DC.

[37] Wigdor, Alexandra K., and Bert F. Green. 1991. Performance Assessment for the Workplace, Volume II: Technical Issues. Washington, D.C.: National Academy Press.

[38] Wonnacott, Ronald J. and Thomas H. Wonnacott. 1979. Econometrics. Second Edition. New York: John Wiley \& Sons. 
Figure 1: Model of Intergenerational Skill Transfer

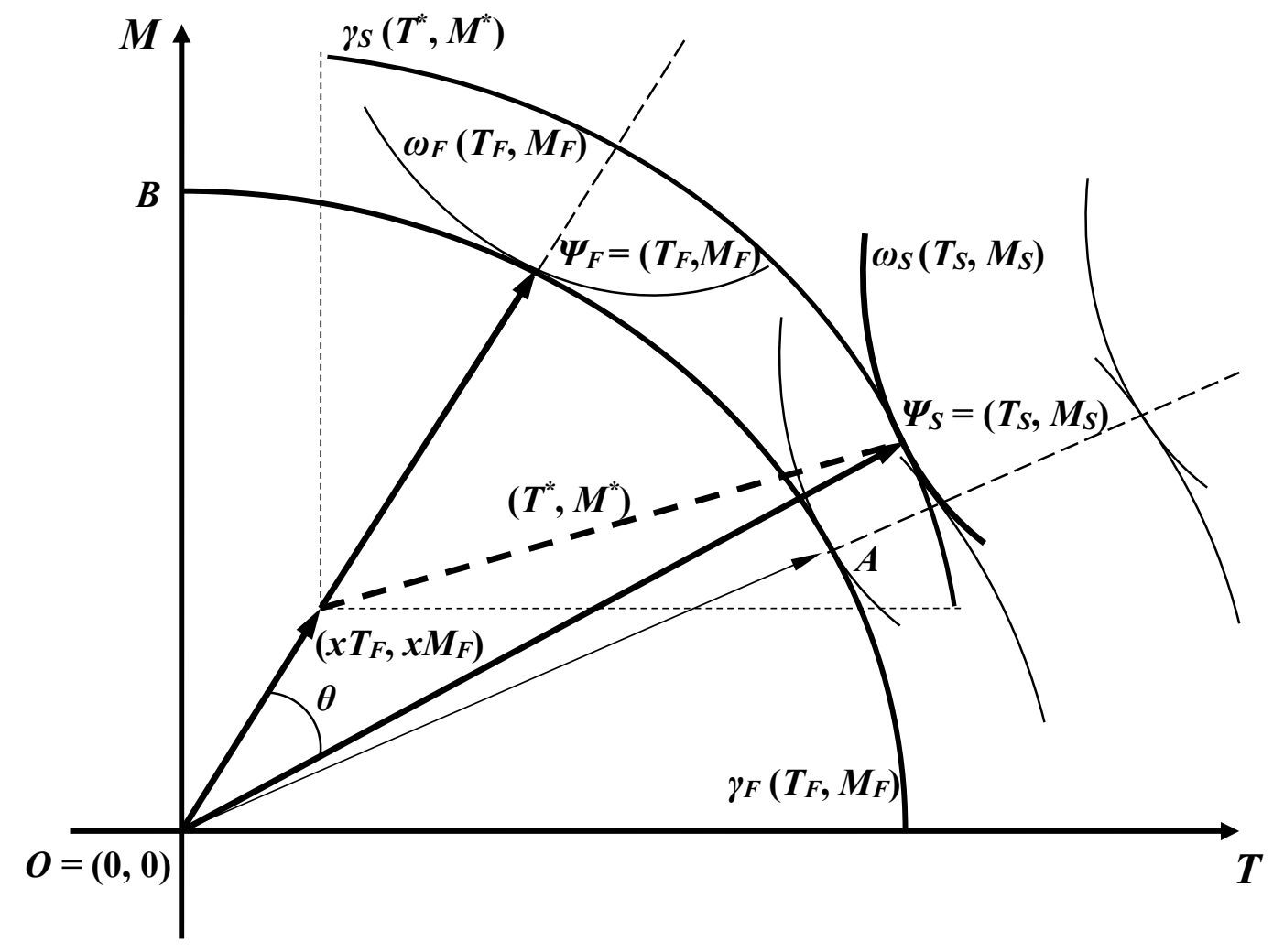


Panel A. Distribution of Correlation Coefficients for Father-Son, Whites

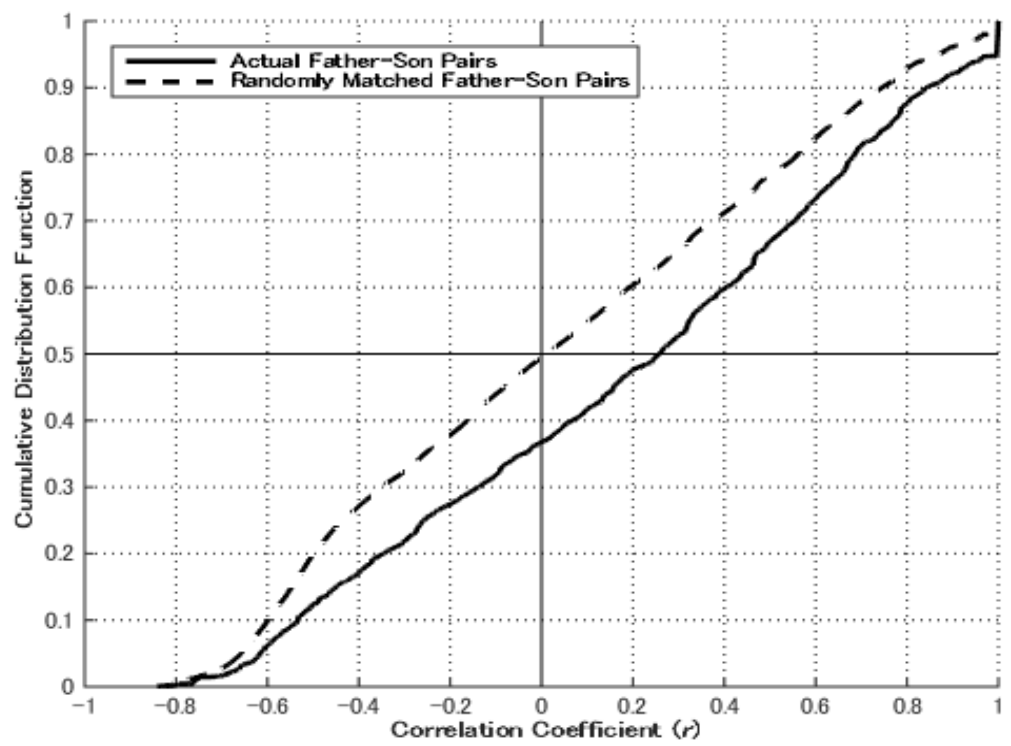

Panel B. Distribution of Correlation Coefficients for Father-Son, Blacks

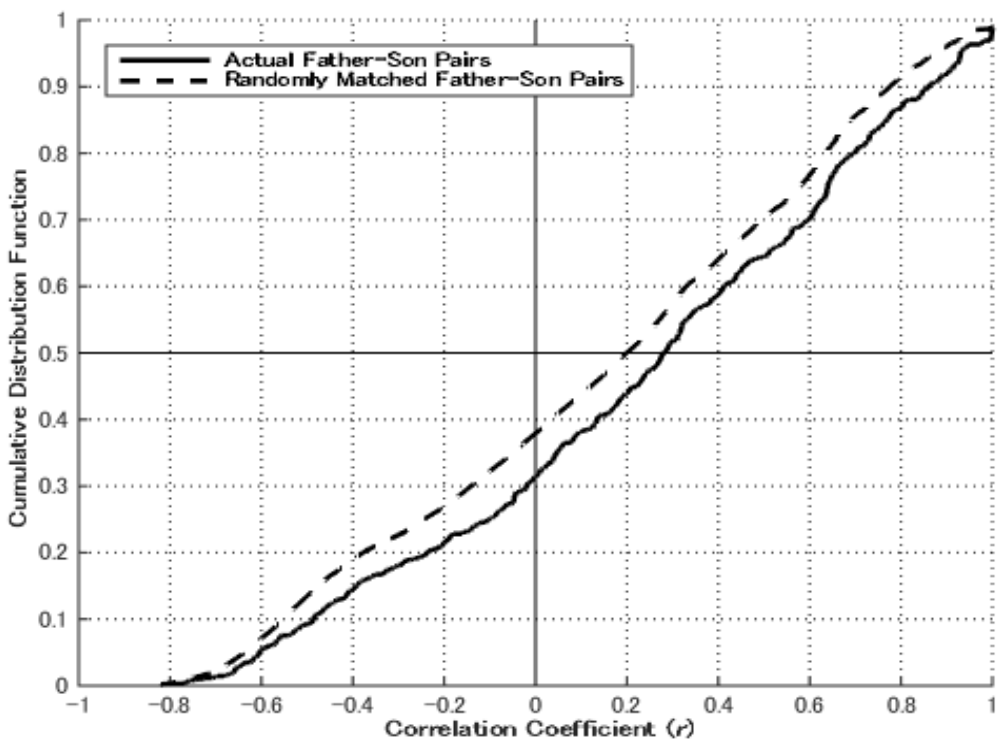

Panel C. Difference between Actual Correlation and Correlation Generated by Random Matching

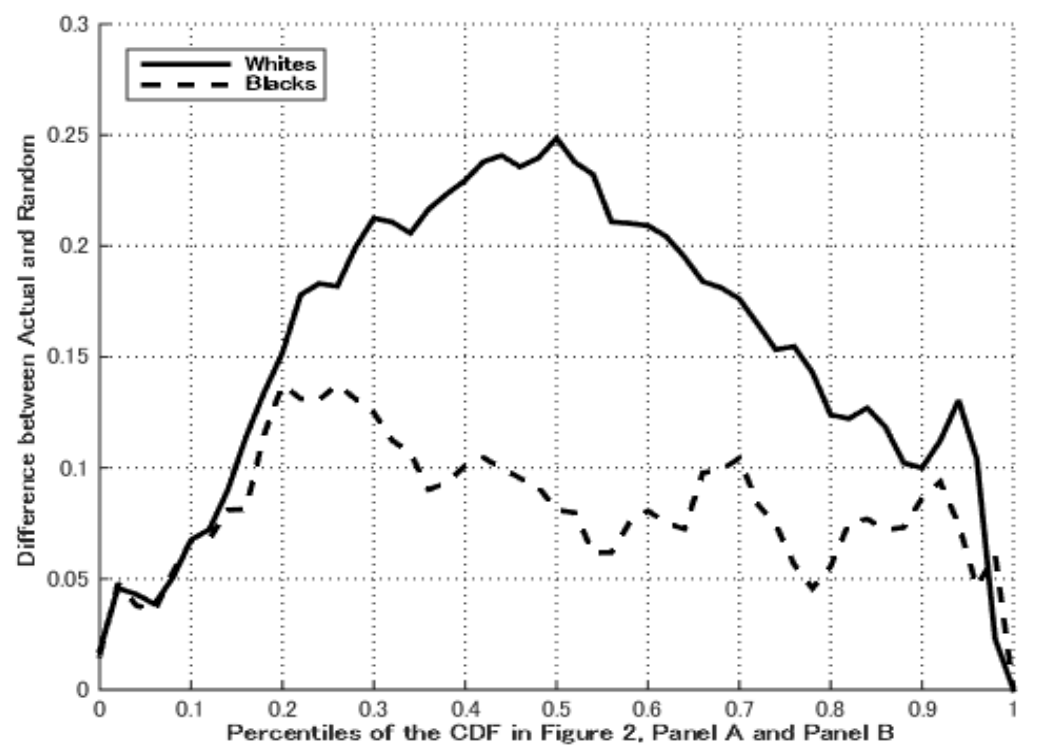

Note: The sons' information is taken from the 1993 wave. The correlation coefficient between father-son skill vectors is computed using the DOT skill variables listed in

Appendix Table 1. Panel $\mathrm{C}$ takes the difference between the actual correlation coefficient and the randomly matched correlation coefficient by the percentiles of the CDF in Panel A for whites and Panel B for blacks. 
Figure 3: OLS and Quantile Regression Estimates for Wage Model: 1993
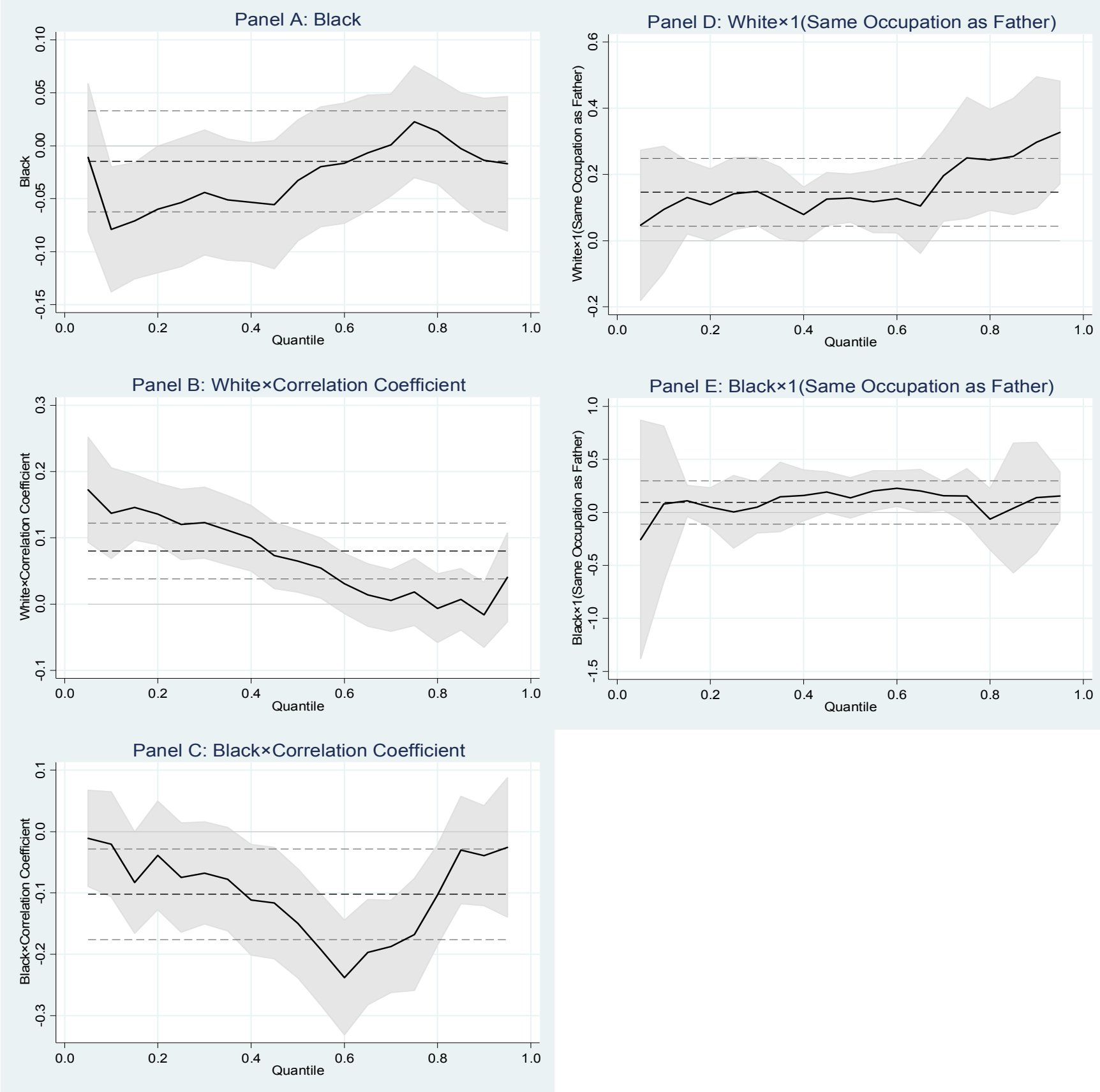

Note: The correlation coefficient between the father's skill vector and the son's vector is computed using all the DOT skill variables. See Appendix Table 1 for a detailed description of the DOT skill varibles. All regressions include son's AFQT score and its square, age, father's education, and father's DOT skill variables. The quantile regression estimates are the solid curve, the shaded grey area depicts the 90 percent confidence interval for the quantile regression estimates. The dashed line depicts the OLS estimate, and the two light dotted lines is the 90 percent confidence interval for the OLS estimate. Robust standard errors are used to compute confidence intervals. 
Table 1: Comparison of Means and Standard Deviations of Selected Variables

\begin{tabular}{|c|c|c|c|c|c|c|c|c|c|c|c|c|}
\hline \multirow[b]{3}{*}{ Variable } & \multicolumn{4}{|c|}{ Father } & \multicolumn{4}{|c|}{ Son, 1993 Wave } & \multicolumn{4}{|c|}{ Son, 2000 Wave } \\
\hline & \multicolumn{2}{|c|}{ Whites } & \multicolumn{2}{|c|}{ Blacks } & \multicolumn{2}{|c|}{ Whites } & \multicolumn{2}{|c|}{ Blacks } & \multicolumn{2}{|c|}{ Whites } & \multicolumn{2}{|c|}{ Blacks } \\
\hline & Mean & SD & Mean & SD & Mean & SD & Mean & SD & Mean & SD & Mean & SD \\
\hline Age & 43.13 & 6.768 & 42.85 & 7.270 & 32.09 & 2.294 & 31.82 & 2.267 & 39.13 & 2.304 & 38.93 & 2.274 \\
\hline Experience & & & & & 10.93 & 3.942 & 9.121 & 4.162 & 17.65 & 4.669 & 14.94 & 5.646 \\
\hline Log(wage) & & & & & 2.429 & 0.519 & 2.109 & 0.499 & 2.639 & 0.578 & 2.256 & 0.517 \\
\hline \multicolumn{13}{|l|}{ Cognitive Skills } \\
\hline Math & 0.316 & 0.839 & -0.360 & 0.767 & 0.257 & 0.837 & -0.265 & 0.849 & 0.377 & 0.829 & -0.138 & 0.898 \\
\hline Reasoning & 0.305 & 0.816 & -0.362 & 0.757 & 0.259 & 0.847 & -0.271 & 0.881 & 0.379 & 0.815 & -0.124 & 0.904 \\
\hline Language & 0.205 & 0.828 & -0.440 & 0.725 & 0.168 & 0.839 & -0.327 & 0.851 & 0.273 & 0.814 & -0.204 & 0.873 \\
\hline General Learning & 0.269 & 0.798 & -0.329 & 0.652 & 0.226 & 0.796 & -0.234 & 0.795 & 0.322 & 0.788 & -0.115 & 0.820 \\
\hline Verbal & 0.184 & 0.880 & -0.468 & 0.741 & 0.171 & 0.888 & -0.300 & 0.872 & 0.278 & 0.866 & -0.199 & 0.906 \\
\hline Numerical & 0.289 & 0.821 & -0.369 & 0.739 & 0.243 & 0.821 & -0.232 & 0.819 & 0.327 & 0.806 & -0.114 & 0.824 \\
\hline Creative Activity & 0.350 & 0.703 & -0.175 & 0.801 & 0.286 & 0.749 & -0.135 & 0.826 & 0.387 & 0.687 & -0.029 & 0.826 \\
\hline Plan Activity & 0.312 & 0.961 & -0.172 & 0.700 & 0.236 & 0.905 & -0.116 & 0.690 & 0.393 & 0.955 & 0.040 & 0.838 \\
\hline Data & 0.376 & 0.866 & -0.303 & 0.868 & 0.332 & 0.902 & -0.225 & 0.902 & 0.464 & 0.884 & -0.064 & 0.975 \\
\hline Talking, Hearing & -0.050 & 0.839 & -0.409 & 0.772 & 0.016 & 0.814 & -0.285 & 0.808 & 0.116 & 0.799 & -0.178 & 0.823 \\
\hline Communicate Data & -0.076 & 0.834 & -0.469 & 0.670 & -0.009 & 0.810 & -0.268 & 0.805 & 0.042 & 0.788 & -0.205 & 0.775 \\
\hline Business Contact & -0.112 & 0.872 & -0.241 & 0.626 & -0.096 & 0.868 & -0.191 & 0.688 & -0.053 & 0.887 & -0.134 & 0.738 \\
\hline Good of People & -0.305 & 0.806 & -0.484 & 0.697 & -0.241 & 0.758 & -0.219 & 0.764 & -0.240 & 0.769 & -0.280 & 0.764 \\
\hline People & 0.136 & 0.864 & -0.304 & 0.746 & 0.107 & 0.832 & -0.208 & 0.805 & 0.213 & 0.814 & -0.078 & 0.826 \\
\hline \multicolumn{13}{|l|}{ Motor Skills } \\
\hline Motor Coordination & 0.015 & 0.693 & 0.138 & 0.591 & -0.078 & 0.691 & -0.093 & 0.666 & -0.107 & 0.682 & -0.105 & 0.634 \\
\hline Form Perception & 0.181 & 0.720 & -0.139 & 0.681 & 0.130 & 0.684 & -0.205 & 0.665 & 0.153 & 0.666 & -0.139 & 0.667 \\
\hline Spatial Perception & 0.477 & 0.748 & 0.350 & 0.699 & 0.387 & 0.743 & 0.103 & 0.710 & 0.436 & 0.734 & 0.233 & 0.710 \\
\hline Finger Dexterity & -0.083 & 0.748 & -0.184 & 0.645 & -0.133 & 0.721 & -0.273 & 0.656 & -0.166 & 0.711 & -0.313 & 0.607 \\
\hline Manual Dexterity & -0.039 & 0.896 & 0.294 & 0.681 & -0.089 & 0.896 & 0.091 & 0.749 & -0.139 & 0.915 & -0.023 & 0.779 \\
\hline Eye-Hand-Foot Coord. & 0.149 & 0.845 & 0.488 & 0.847 & 0.098 & 0.808 & 0.271 & 0.846 & 0.092 & 0.790 & 0.280 & 0.851 \\
\hline Precisely Set Limits & 0.035 & 0.819 & 0.107 & 0.769 & 0.018 & 0.778 & 0.022 & 0.739 & -0.054 & 0.770 & -0.049 & 0.746 \\
\hline Make Judgments & 0.398 & 0.779 & 0.182 & 0.756 & 0.348 & 0.759 & 0.053 & 0.724 & 0.371 & 0.746 & 0.090 & 0.750 \\
\hline Perform Variety of Duties & -0.004 & 0.684 & -0.135 & 0.692 & 0.005 & 0.652 & -0.151 & 0.636 & 0.036 & 0.637 & -0.115 & 0.638 \\
\hline Things & 0.132 & 0.891 & 0.182 & 0.745 & 0.030 & 0.863 & -0.049 & 0.776 & 0.010 & 0.867 & -0.022 & 0.780 \\
\hline Climbing & 0.192 & 0.914 & 0.319 & 0.914 & 0.137 & 0.883 & 0.223 & 0.900 & 0.074 & 0.830 & 0.149 & 0.836 \\
\hline Stooping & 0.096 & 0.828 & 0.432 & 0.825 & 0.063 & 0.829 & 0.229 & 0.843 & 0.001 & 0.801 & 0.165 & 0.814 \\
\hline Reaching & -0.214 & 0.894 & 0.260 & 0.576 & -0.248 & 0.893 & 0.067 & 0.760 & -0.359 & 0.916 & -0.063 & 0.824 \\
\hline Seeing & 0.113 & 0.717 & 0.191 & 0.619 & 0.066 & 0.704 & 0.037 & 0.676 & 0.019 & 0.705 & 0.027 & 0.668 \\
\hline $\mathrm{N}$ & \multicolumn{2}{|c|}{1854} & \multicolumn{2}{|c|}{715} & \multicolumn{2}{|c|}{1752} & \multicolumn{2}{|c|}{601} & \multicolumn{2}{|c|}{1594} & \multicolumn{2}{|c|}{564} \\
\hline
\end{tabular}

1970 census occupation. 
Son

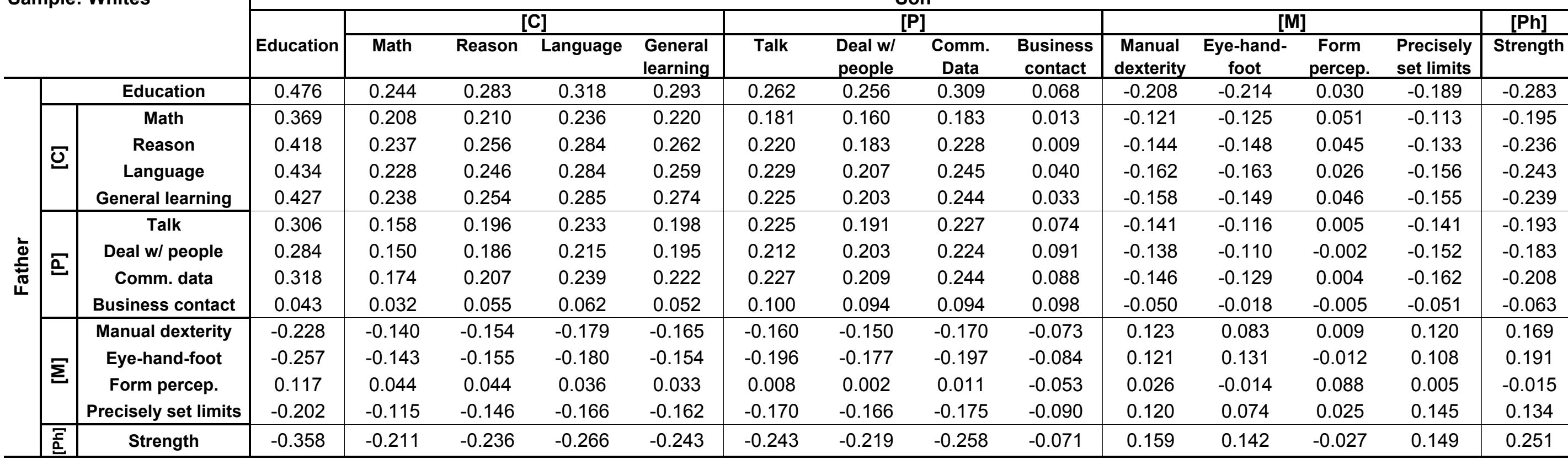

Sample: Blacks

\begin{tabular}{|c|c|c|c|c|c|c|c|c|c|c|c|c|c|c|c|c|}
\hline \multirow{3}{*}{\multicolumn{3}{|c|}{ Sample: Blacks }} & \multicolumn{14}{|c|}{ Son } \\
\hline & & & \multirow[b]{2}{*}{ Education } & \multicolumn{4}{|c|}{ [C] } & \multicolumn{4}{|c|}{$[\mathbf{P}]$} & \multicolumn{4}{|c|}{$[\mathrm{M}]$} & \multirow{2}{*}{$\frac{[\mathrm{Ph}]}{\text { Strength }}$} \\
\hline & & & & Math & Reason & Language & $\begin{array}{r}\text { General } \\
\text { learning }\end{array}$ & Talk & $\begin{array}{l}\text { Deal w/ } \\
\text { people }\end{array}$ & $\begin{array}{c}\text { Comm. } \\
\text { Data }\end{array}$ & $\begin{array}{c}\text { Business } \\
\text { contact }\end{array}$ & $\begin{array}{c}\text { Manual } \\
\text { dexterity }\end{array}$ & $\begin{array}{c}\text { Eye-hand- } \\
\text { foot }\end{array}$ & $\begin{array}{c}\text { Form } \\
\text { percep. }\end{array}$ & $\begin{array}{l}\text { Precisely } \\
\text { set limits }\end{array}$ & \\
\hline \multirow{14}{*}{ 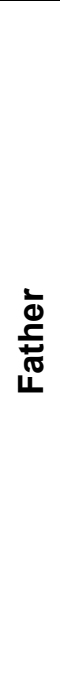 } & & Education & 0.294 & 0.172 & 0.188 & 0.191 & 0.191 & 0.220 & 0.222 & 0.240 & 0.126 & -0.105 & -0.131 & 0.074 & -0.101 & -0.195 \\
\hline & \multirow{4}{*}{$\bar{U}$} & Math & 0.207 & 0.157 & 0.177 & 0.185 & 0.183 & 0.120 & 0.113 & 0.142 & 0.053 & -0.053 & -0.043 & 0.120 & -0.053 & -0.144 \\
\hline & & Reason & 0.227 & 0.203 & 0.225 & 0.226 & 0.230 & 0.149 & 0.151 & 0.171 & 0.082 & -0.068 & -0.048 & 0.137 & -0.035 & -0.177 \\
\hline & & Language & 0.217 & 0.191 & 0.216 & 0.230 & 0.231 & 0.174 & 0.168 & 0.190 & 0.108 & -0.080 & -0.089 & 0.111 & -0.051 & -0.188 \\
\hline & & General learning & 0.215 & 0.199 & 0.228 & 0.227 & 0.239 & 0.177 & 0.181 & 0.202 & 0.107 & -0.101 & -0.089 & 0.114 & -0.055 & -0.196 \\
\hline & \multirow{4}{*}{ ㄴ } & Talk & 0.133 & 0.161 & 0.174 & 0.172 & 0.172 & 0.131 & 0.116 & 0.140 & 0.097 & -0.070 & -0.052 & 0.088 & -0.018 & -0.157 \\
\hline & & Deal w/ people & 0.115 & 0.148 & 0.164 & 0.173 & 0.171 & 0.148 & 0.156 & 0.157 & 0.135 & -0.119 & -0.086 & 0.029 & -0.057 & -0.166 \\
\hline & & Comm. data & 0.149 & 0.176 & 0.184 & 0.200 & 0.202 & 0.173 & 0.183 & 0.181 & 0.160 & -0.159 & -0.120 & 0.039 & -0.060 & -0.203 \\
\hline & & Business contact & 0.037 & 0.080 & 0.069 & 0.081 & 0.091 & 0.048 & 0.078 & 0.090 & 0.085 & -0.078 & -0.056 & -0.005 & -0.039 & -0.104 \\
\hline & \multirow{4}{*}{$\boldsymbol{\Sigma}$} & Manual dexterity & -0.074 & -0.056 & -0.063 & -0.067 & -0.086 & -0.075 & -0.098 & -0.076 & -0.090 & 0.050 & 0.101 & -0.019 & 0.016 & 0.070 \\
\hline & & Eye-hand-foot & -0.146 & -0.105 & -0.093 & -0.145 & -0.115 & -0.128 & -0.134 & -0.126 & -0.094 & 0.105 & 0.109 & -0.007 & 0.047 & 0.136 \\
\hline & & Form percep. & 0.155 & 0.113 & 0.122 & 0.142 & 0.127 & 0.060 & 0.085 & 0.095 & 0.036 & -0.067 & -0.018 & 0.084 & -0.035 & -0.141 \\
\hline & & Precisely set limits & 0.052 & -0.020 & -0.047 & -0.035 & -0.063 & -0.085 & -0.066 & -0.070 & -0.079 & 0.054 & 0.088 & 0.044 & 0.041 & 0.046 \\
\hline & $\frac{\mathrm{T}}{2}$ & Strength & -0.214 & -0.187 & -0.211 & -0.216 & -0.220 & -0.188 & -0.218 & -0.221 & -0.143 & 0.133 & 0.100 & -0.083 & 0.077 & 0.200 \\
\hline
\end{tabular}

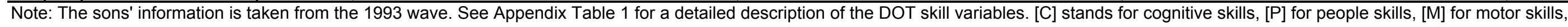
and $[\mathrm{Ph}]$ for physical strength. 
Table 3: Effect of Father's DOT Skills on Son's DOT Skills

Independent Variables:

Separate Regression for Each DOT Skill

Father's Math Cognitive Skills

\section{Father's Reason}

Father's General Intelligence

\section{Father's Verbal}

Father's Plan Activity

Father's Make Evaluations

\section{Father's Data}

\begin{tabular}{l} 
\\
\hline People Skills
\end{tabular}

Father's Dealing with People

\section{Father's Talking/Hearing}

Father's Communicate Data

Father's Business Contact

Father's People

\begin{tabular}{ll}
$0.049^{* * *}$ & 0.006 \\
$(0.019)$ & $(0.031)$ \\
$0.044^{* *}$ & 0.029 \\
$(0.019)$ & $(0.032)$ \\
$0.048^{* * *}$ & $0.057^{*}$ \\
$(0.018)$ & $(0.033)$ \\
$0.056^{* * *}$ & $0.060^{*}$ \\
$(0.019)$ & $(0.035)$ \\
$0.054^{* * *}$ & -0.006 \\
$(0.017)$ & $(0.027)$ \\
$0.042^{* *}$ & $0.052{ }^{*}$ \\
$(0.018)$ & $(0.030)$ \\
$0.060^{* * *}$ & 0.024 \\
$(0.020)$ & $(0.029)$ \\
\hline & \\
$0.069^{* * *}$ & $0.090{ }^{* *}$ \\
$(0.018)$ & $(0.033)$ \\
$0.068^{* * *}$ & 0.039 \\
$(0.018)$ & $(0.029)$ \\
$0.052^{* * *}$ & $0.063 *$ \\
$(0.018)$ & $(0.038)$ \\
$0.084^{* * *}$ & 0.037 \\
$(0.021)$ & $(0.037)$ \\
$0.046^{* * *}$ & $0.074{ }^{* * *}$ \\
$(0.018)$ & $(0.028)$
\end{tabular}

Blacks (2)

hites (1)

variables $(r$

between 1990 and 2000. Regressions include son's education, a quadratic in son's AFQT score, a cubic in son's labor-market experience, son's place of residence, father's education, a dummy for whether father and son work in the same occupation, and year dummies. Robust standard errors clustered at the individual level are in parentheses. ${ }^{*} p<0.1,{ }^{* *} p<0.05,{ }^{* * *} p<0.01$.

\begin{tabular}{|c|c|c|}
\hline \multirow{2}{*}{$\begin{array}{l}\text { Independent Variables: } \\
\text { Separate Regression for Each DOT Skill }\end{array}$} & Whites & Blacks \\
\hline & $(3)$ & $(4)$ \\
\hline \multicolumn{3}{|l|}{$\begin{array}{ll} & \text { Motor Skills } \\
\end{array}$} \\
\hline Father's Spatial Perception & $\begin{array}{l}0.056^{* * *} \\
(0.019)\end{array}$ & $\begin{array}{l}0.089 * * * \\
(0.031)\end{array}$ \\
\hline Father's Manual Dexterity & $\begin{array}{l}0.033^{*} \\
(0.020)\end{array}$ & $\begin{array}{l}0.063^{* *} \\
(0.032)\end{array}$ \\
\hline Father's Eye-Hand-Foot Coordination & $\begin{array}{l}0.043 * * \\
(0.018)\end{array}$ & $\begin{array}{l}0.061 \text { ** } \\
(0.028)\end{array}$ \\
\hline Father's Form Perception & $\begin{array}{l}0.043 * * \\
(0.018)\end{array}$ & $\begin{array}{l}0.048 \text { * } \\
(0.029)\end{array}$ \\
\hline Father's Finger Dexterity & $\begin{array}{l}0.036 * \\
(0.019)\end{array}$ & $\begin{array}{l}0.073^{* *} \\
(0.030)\end{array}$ \\
\hline Father's Precisely Set Limits & $\begin{array}{l}0.077^{* * *} \\
(0.018)\end{array}$ & $\begin{array}{l}0.081^{* * *} \\
(0.028)\end{array}$ \\
\hline Father's Things & $\begin{array}{l}0.041^{* *} \\
(0.018)\end{array}$ & $\begin{array}{l}0.075^{* *} \\
(0.031)\end{array}$ \\
\hline \multicolumn{3}{|c|}{ Physical Strength } \\
\hline Father's Strength & $\begin{array}{l}0.072 * * * \\
(0.019)\end{array}$ & $\begin{array}{l}0.056 \\
(0.037)\end{array}$ \\
\hline Father's Climbing & $\begin{array}{l}0.085^{* * *} \\
(0.019)\end{array}$ & $\begin{array}{l}0.042 \\
(0.028)\end{array}$ \\
\hline Father's Stooping & $\begin{array}{l}0.054^{* * *} \\
(0.019)\end{array}$ & $\begin{array}{l}0.015 \\
(0.028)\end{array}$ \\
\hline Father's Reaching & $\begin{array}{l}0.054^{* * *} \\
(0.019)\end{array}$ & $\begin{array}{l}0.018 \\
(0.045)\end{array}$ \\
\hline Father's Seeing & $\begin{array}{l}0.069^{* * *} \\
(0.018)\end{array}$ & $\begin{array}{l}0.048 \\
(0.031)\end{array}$ \\
\hline
\end{tabular}


Table 4: Means and Standard Deviations of the Correlation Coefficient of Father-Son Skill Vectors

\begin{tabular}{|c|c|c|c|c|c|c|}
\hline \multirow[b]{3}{*}{ Father's Education } & \multicolumn{2}{|c|}{ Correlation Coefficient } & \multirow{2}{*}{$\begin{array}{c}\text { Fraction of Father- } \\
\text { Son Pairs in Same } \\
\text { Occupation }\end{array}$} & \multicolumn{2}{|c|}{ Correlation Coefficient } & \multirow{2}{*}{$\begin{array}{c}\text { Fraction of Father- } \\
\text { Son Pairs in Same } \\
\text { Occupation }\end{array}$} \\
\hline & $\begin{array}{l}\text { All Father-Son } \\
\text { Pairs }\end{array}$ & $\begin{array}{l}\text { Exclude Pairs in } \\
\text { Same Occupation }\end{array}$ & & $\begin{array}{l}\text { All Father-Son } \\
\text { Pairs }\end{array}$ & $\begin{array}{l}\text { Exclude Pairs in } \\
\text { Same Occupation }\end{array}$ & \\
\hline & Mean $\quad$ SD & Mean SD & Mean SD & Mean $\quad$ SD & Mean SD & Mean SD \\
\hline 1993 Wave & \multicolumn{3}{|c|}{ Whites } & \multicolumn{3}{|c|}{ Blacks } \\
\hline Less than High School & $N=467$ & $N=441$ & $N=467$ & $N=313$ & $N=301$ & $N=313$ \\
\hline High School & $N=647$ & $N=611$ & $N=647$ & $N=209$ & $N=206$ & $N=209$ \\
\hline Some College & $N=232$ & $N=218$ & $N=232$ & $N=43$ & $N=43$ & $N=43$ \\
\hline College & $N=406$ & $N=391$ & $N=406$ & $N=36$ & $N=34$ & $N=36$ \\
\hline Total & $\begin{array}{c}0.191 \quad 0.509 \\
N=1752\end{array}$ & $\begin{array}{c}0.146 \quad 0.485 \\
N=1661\end{array}$ & $\begin{array}{c}0.053 \quad 0.225 \\
N=1752\end{array}$ & $\begin{array}{c}0.216 \quad 0.484 \\
N=601\end{array}$ & $\begin{array}{c}0.192 \quad 0.471 \\
N=584\end{array}$ & $\begin{array}{c}0.030 \quad 0.170 \\
N=601\end{array}$ \\
\hline 2000 Wave & \multicolumn{3}{|c|}{ Whites } & \multicolumn{3}{|c|}{ Blacks } \\
\hline Less than High School & $\begin{array}{c}0.172 \quad 0.521 \\
N=434\end{array}$ & $\begin{array}{c}0.114 \quad 0.489 \\
N=405\end{array}$ & $\begin{array}{c}0.066 \quad 0.249 \\
N=434\end{array}$ & $\begin{array}{c}0.228 \quad 0.514 \\
N=292\end{array}$ & $\begin{array}{c}0.196 \quad 0.499 \\
N=280\end{array}$ & $\begin{array}{c}0.040 \quad 0.196 \\
N=292\end{array}$ \\
\hline High School & $\begin{array}{c}0.169 \quad 0.530 \\
N=592\end{array}$ & $\begin{array}{c}0.103 \quad 0.494 \\
N=551\end{array}$ & $\begin{array}{c}0.073 \quad 0.261 \\
N=592\end{array}$ & $\begin{array}{c}0.059 \quad 0.492 \\
N=200\end{array}$ & $\begin{array}{c}0.033 \quad 0.473 \\
N=195\end{array}$ & $\begin{array}{c}0.027 \quad 0.161 \\
N=200\end{array}$ \\
\hline Some College & $\begin{array}{c}0.188 \quad 0.536 \\
N=212\end{array}$ & $\begin{array}{c}0.142 \quad 0.514 \\
N=201\end{array}$ & $\begin{array}{c}0.053 \quad 0.225 \\
N=212\end{array}$ & $\begin{array}{c}-0.044 \quad 0.440 \\
N=39\end{array}$ & $\begin{array}{c}-0.044 \quad 0.440 \\
N=39\end{array}$ & $\begin{array}{c}0.000 \quad 0.000 \\
N=39\end{array}$ \\
\hline College & $\begin{array}{c}0.331 \quad 0.468 \\
N=356\end{array}$ & $\begin{array}{c}0.287 \quad 0.450 \\
N=334\end{array}$ & $\begin{array}{c}0.061 \quad 0.240 \\
N=356\end{array}$ & $\begin{array}{c}0.267 \quad 0.489 \\
N=33\end{array}$ & $\begin{array}{c}0.203 \quad 0.456 \\
N=31\end{array}$ & $\begin{array}{c}0.080 \quad 0.275 \\
N=33\end{array}$ \\
\hline Total & $\begin{array}{c}0.210 \quad 0.519 \\
N=1594\end{array}$ & $\begin{array}{c}0.154 \quad 0.491 \\
N=1491\end{array}$ & $\begin{array}{c}0.066 \quad 0.248 \\
N=1594\end{array}$ & $\begin{array}{c}0.147 \quad 0.507 \\
N=564\end{array}$ & $\begin{array}{c}0.117 \quad 0.490 \\
N=545\end{array}$ & $\begin{array}{c}0.034 \quad 0.182 \\
N=564\end{array}$ \\
\hline
\end{tabular}

Note: The numbers in the table are means and standard deviations of the column variables conditional on row segments. The correlation coefficient between the father's skill vector and the son's vector is computed using all the DOT skill variables. See Appendix Table 1 for a detailed description of the DOT skill variables. 
Table 5: OLS Estimates of Wage Equation

\begin{tabular}{|c|c|c|c|c|c|c|}
\hline \multirow[b]{2}{*}{ Variables } & \multicolumn{3}{|c|}{1993 Wave } & \multirow{2}{*}{$\begin{array}{c}1996 \text { Wave } \\
(4)\end{array}$} & \multirow{2}{*}{$\begin{array}{c}1998 \text { Wave } \\
(5)\end{array}$} & \multirow{2}{*}{$\frac{2000 \text { Wave }}{(6)}$} \\
\hline & (1) & $(2)$ & (3) & & & \\
\hline Blacks & $\begin{array}{l}-0.091^{* \star *} \\
(0.026)\end{array}$ & $\begin{array}{l}-0.051 * \\
(0.027)\end{array}$ & $\begin{array}{l}-0.015 \\
(0.029)\end{array}$ & $\begin{array}{l}-0.005 \\
(0.032)\end{array}$ & $\begin{array}{l}-0.023 \\
(0.031)\end{array}$ & $\begin{array}{l}-0.052 \text { * } \\
(0.030)\end{array}$ \\
\hline Whites $\times$ Correlation Coefficient $(r)$ & & & $\begin{array}{l}0.080^{* * *} \\
(0.026)\end{array}$ & $\begin{array}{r}0.035 \\
(0.027)\end{array}$ & $\begin{array}{c}0.032 \\
(0.028)\end{array}$ & $\begin{array}{l}0.063^{* *} \\
(0.030)\end{array}$ \\
\hline Blacks $\times$ Correlation Coefficient $(r)$ & & & $\begin{array}{l}-0.102 \text { ** } \\
(0.045)\end{array}$ & $\begin{array}{l}-0.113^{* *} \\
(0.049)\end{array}$ & $\begin{array}{l}-0.109 * * \\
(0.045)\end{array}$ & $\begin{array}{l}-0.038 \\
(0.047)\end{array}$ \\
\hline Whites $\times \mathbf{1}$ (Same Occupation as Father) & & & $\begin{array}{l}0.146 \text { ** } \\
(0.062)\end{array}$ & $\begin{array}{r}0.109 \\
(0.077)\end{array}$ & $\begin{array}{c}0.052 \\
(0.060)\end{array}$ & $\begin{array}{c}0.064 \\
(0.070)\end{array}$ \\
\hline Blacks $\times \mathbf{1}$ (Same Occupation as Father) & & & $\begin{array}{c}0.095 \\
(0.124)\end{array}$ & $\begin{array}{c}0.102 \\
(0.100)\end{array}$ & $\begin{array}{c}0.143 \\
(0.107)\end{array}$ & $\begin{array}{c}0.071 \\
(0.088)\end{array}$ \\
\hline Father's Education & & $\begin{array}{l}0.013 * * * \\
(0.004)\end{array}$ & $\begin{array}{l}0.013^{* * *} \\
(0.004)\end{array}$ & $\begin{array}{l}0.013^{* * *} \\
(0.005)\end{array}$ & $\begin{array}{l}0.012 \text { ** } \\
(0.005)\end{array}$ & $\begin{array}{l}0.012 \text { ** } \\
(0.005)\end{array}$ \\
\hline Controls for Father's Skills & No & Yes & Yes & Yes & Yes & Yes \\
\hline $\mathrm{R}^{2}$ & 0.203 & 0.236 & 0.247 & 0.260 & 0.272 & 0.278 \\
\hline $\mathrm{N}$ & 2137 & 2137 & 2137 & 2149 & 2070 & 1978 \\
\hline
\end{tabular}

Note: The correlation coefficient between the father's skill vector and the son's vector is computed using all the DOT skill variables. See Appendix Table 1 for a detailed description of the DOT skill varibles. All regressions include son's AFQT score and its square, and age. The specifications in columns (2)-(6) add father's education and father's DOT skill variables. Robust standard errors are in parentheses. ${ }^{*} p<0.1,{ }^{* *} p<0.05,{ }^{* * *} p<0.01$. 
Table 6: Total Contribution of Skill Correlation between Father-Son and Nepotism to Change in the Relative Wage Gap: Comparison between: 1993 and 2000

\begin{tabular}{ll|ccc} 
Panel A: Log Wage & & Coef. & SE & N \\
\hline Current Year: 2000 & White (A) & 2.630 & 0.015 & 1453 \\
& Black (B) & 2.246 & 0.023 & 525 \\
Base Year: 1993 & White (C) & 2.418 & 0.013 & 1579 \\
& Black (D) & 2.101 & 0.022 & 558 \\
\hline Panel B: Log Wage Gap & & Coef. & SE \\
\hline & Current Year (A-B) & 0.385 & 0.028 \\
& Base Year (C-D) & 0.317 & 0.025 \\
\hline Panel C: Detailed Decomposition & 0.068 & 0.038 \\
\hline Main Effect & Change in Log Wage Gap (A-B)-(C-D) & Coef. & SE \\
& Correlation Coefficient $(r)$ & \multicolumn{2}{|}{} \\
Race Interaction Effect & 1(Same Occupation as Father) & -0.007 & 0.005 \\
& Correlation Coefficient $(r)$ & 0.001 & 0.003 \\
Year Interaction Effect & 1(Same Occupation as Father) & 0.001 & 0.004 \\
& Correlation Coefficient $(r)$ & 0.000 & 0.002 \\
Race-Year Interacton Effect & \multicolumn{2}{|c}{} & \\
& 1(Same Occupation as Father) & -0.003 & 0.004 \\
& Correlation Coefficient $(r)$ & 0.005 \\
& 1(Same Occupation as Father) & -0.021 & 0.017 \\
& & 0.000 & 0.012 \\
\hline
\end{tabular}




\begin{tabular}{l|c|l}
\hline VARIABLE & $\begin{array}{c}\text { DOT JOB } \\
\text { COMPONENT }\end{array}$ & DESCRIPTION \\
\hline
\end{tabular}

\section{Cognitive-Skill Variables:}

Relation to Data Worker Function Complexity at which worker performs job in relation to data, from highest to lowest:

Reasoning GED

Mathematics GED

Language GED

Specific SVP

Vocational

Preparation

General Learning Aptitude

Verbal Aptitude

Numerical Aptitude

Clerical Aptitude

Perception

Plan Activity Temperaments

Make Evaluations Temperaments

Creative Activity Interest Factor

Esteem of Others Interest Factor

Relation to People Worker Function

Deal with People Temperaments

Influence People Temperaments

Interpret Feelings Temperaments

Talking and/or Physical

Hearing Demands

Communicate Interest Factor

Data

Business Contact Interest Factor

Work for the Good Interest Factor of People
Synthesizing, Coordinating, Analyzing, Compiling, Computing, Copying, Comparing.

General educational development (GED) in reasoning required for job, ranging from being able to apply logical or scientific thinking to wide range of intellectual and practical problems, to being able to apply commonsense understanding to carry out simple instructions.

GED in mathematics required for job, from knowledge of advanced calculus, modern algebra and statistics; algebra, geometry and shop math; to simple addition and subtraction.

GED in language required for job, from reading literature, writing editorials and speeches, and conversant in persuasive speaking and debate; to reading at rate of 95-120 words per minute or vocabulary of 2500 words and writing and speaking simple sentences.

SVP is the amount of time required to learn the techniques, acquire the information, and develop the facility needed for average performance in a specific job-worker situation.

Ability to "catch on" or understand instructions and underlying principles; ability to reason and make judgments.

Ability to understand meaning of words and to use them effectively. Ability to comprehend language, to understand relationships between words, and to understand meanings of whole sentences and paragraphs.

Ability to perform arithmetic operations quickly and accurately.

Ability to perceive pertinent detail in verbal or tabular material. Ability to observe differences in copy, to proofread words and numbers, and to avoid perceptual errors in arithmetic computation. A measure of perception which is required in many industrial jobs even when the job does not have verbal or numerical content.

Adaptability to accepting responsibility for the direction, control or planning of an activity.

Adaptability to making generalizations, evaluations, or decisions based on sensory or judgmental criteria.

A preference for activities of an abstract and creative nature versus a preference for activities of a routine, concrete, organized nature.

A preference for activities resulting in prestige or the esteem of others versus a preference for activities resulting in tangible productive satisfaction.

\section{People-Skills Variables:}

Complexity at which worker performs job in relation to people, from highest to lowest: Mentoring, Negotiating, Instructing, Supervising, Diverting, Persuading, SpeakingSignaling, Serving. Taking Instructions-Helping.

Adaptability to dealing with people beyond giving and receiving instructions.

Adaptability to influencing people in their opinions, attitudes or judgments about ideas or things.

Adaptability to situations involving the interpretation of feeling, ideas or facts in terms of personal viewpoint.

Presence or absence of talking and/or hearing.

A preference for activities concerned with the communication of data versus a preference for activities for dealing with things and objects.

A preference for activities involving business contact with people versus a preference for activities of a scientific and technical nature.

A preference for working for the presumed good of people versus a preference for activities that are carried on in relation to processes, machines, and techniques. 


\begin{tabular}{c|c|c}
\hline VARIABLE & $\begin{array}{c}\text { DOT JOB } \\
\text { COMPONENT }\end{array}$ & DESCRIPTION \\
\hline
\end{tabular}

\section{Motor-Skills Variables:}

Relation to Things Worker Function Complexity at which worker performs job in relation to things: Setting-Up, Precision Working, Operating-Controlling, Driving-Operating, Manipulating, Tending, FeedingOffbearing, Handling.

$\begin{array}{ll}\begin{array}{l}\text { Finger Dexterity } \\ \text { Motor }\end{array} & \begin{array}{l}\text { Aptitude } \\ \text { Aptitude }\end{array} \\ \text { Coordination } & \\ \text { Manual Dexterity } & \text { Aptitude } \\ & \\ \text { Eye-Hand-Foot } & \text { Aptitude } \\ \text { Coordination } & \\ \text { Spatial Perception } & \text { Aptitude }\end{array}$

Form Perception Aptitude

Color Aptitude

Discrimination

Precisely Set Temperaments

Limits

Repetitive Work Temperaments

Make Judgments Temperaments

Perform Variety of Temperaments

Duties

Under Stress Temperaments

$\begin{array}{ll}\text { Strength } & \begin{array}{l}\text { Physical } \\ \text { Strength }\end{array} \\ \text { Climbing } & \text { Physical } \\ & \text { Strength } \\ \text { Stooping } & \begin{array}{l}\text { Physical } \\ \text { Strength }\end{array} \\ \text { Reaching } & \begin{array}{l}\text { Physical } \\ \text { Strength }\end{array} \\ \text { Seeing } & \text { Physical } \\ & \text { Strength }\end{array}$

Ability to move fingers, and manipulate small objects with fingers, rapidly or accurately. Ability to coordinate eyes and hands or fingers rapidly and accurately in making precise movements with speed. Ability to make a movement response accurately and swiftly. Ability to move the hands easily and skillfully. Ability to work with the hands in placing and turning motions.

Ability to move the hand and foot coordinately with each other in accordance with visual stimuli.

Ability to think visually of geometric forms and to comprehend the two-dimensional representation of three-dimensional objects. Ability to recognize the relationships resulting from the movement of objects in space.

Ability to perceive pertinent detail in objects or in pictorial or graphic material. Ability to make visual comparisons and discriminations and see slight differences in shapes and shadings of figures and widths and lengths of lines.

Ability to match or discriminate between colors in terms of hue, saturation, and brilliance. Ability to identify a particular color or color combination from memory and to perceive contrasting color combinations.

Adaptability to situations requiring the precise attainment of set limits, tolerances or standards.

Adaptability to performing repetitive work, or to continuously performing the same work, according to set procedures, sequence, or pace.

Adaptability to making generalizations, judgments, or decisions based on measurable or verifiable criteria.

Adaptability to performing a variety of duties, often changing from one task to another of a different nature without loss of efficiency or composure.

Adaptability to performing under stress when confronted with emergency, critical, unusual, or dangerous situations; or in situations in which working speed and sustained attention are make or break aspects of the job.

\section{Physical-Strength Variables:}

Strength Rating reflects the estimated overall strength requirement of the job (expressed by: sedentary, light, medium, heavy, and very heavy).

Indicate the presence or absence of climbing (climbing and/or balancing).

Indicate the presence or absence of stooping (stooping, kneeling, crouching, and/or crawling).

Indicate the presence or absence of reaching (reaching, handling, fingering and/or feeling).

Indicate the presence or absence of seeing.

Note: Aptitudes (specific capacities or abilities required of an individual in order to facilitate the learning of some task or job duty) have been rated for each occupation, using a five-point scale. The quintiles for rating aptitudes are based on whether the segment of the population possessing the particular aptitude is within: the top 10 percent of the population, the top one-third except for the top 10 percent, the middle third, the lowest third except for the bottom 10 percent, and the lowest 10 percent. Temperaments are coded 1 for the presence of a given temperament and 0 for its absence. Bipolar interest factors signify interests, tastes, and preferences for certain kinds of activities that are entailed in job performance. These interest factors are indicated by 1,0 , and -1 . 


\section{Appendix: Proofs of Propositions P1, P2, P3, and P4}

Except for P3(i), the propositions are proved analytically. P3(i) is solved numerically for various parameter values, because the derivative of $\cos \theta$ with respect to $a_{F}$ is too complicated to solve analytically. The numerical results for $\mathrm{P} 4$ are also provided.

\section{A.1. Proof of Proposition P1}

Proof of P1(i): When the wage and cost functions are defined as in Equations (5) and (6), the first-order conditions in Footnote 5 become the following:

$$
\begin{gathered}
\delta T_{F}^{\delta-1} M_{F}^{1-\delta}=2 a_{F} T_{F}, \\
(1-\delta) T_{F}^{\delta} M_{F}^{-\delta}=2 b M_{F}, \\
\frac{1}{2} T_{S}^{-1 / 2} M_{S}^{1 / 2}=2 a_{S} T^{*}, \\
\frac{1}{2} T_{S}^{1 / 2} M_{S}^{-1 / 2}=2 b M^{*}, \text { and } \\
\left(T_{S}, M_{S}\right)=\left(x T_{F}+T^{*}, x M_{F}+M^{*}\right) .
\end{gathered}
$$

Because of the functional forms of the wage and cost functions, there is no corner solution. By Equations $(A .3),(A .4)$, and $(A .5)$, we have

$$
\begin{gathered}
\frac{M_{S}}{T_{S}}=\frac{x M_{F}+M^{*}}{x T_{F}+T^{*}}=\frac{a_{S}}{b} \frac{T^{*}}{M^{*}} ; \\
16 a_{S} b T^{*} M^{*}=1 .
\end{gathered}
$$

By Equations $(A .6)$ and $(A .7)$, we have

$$
16 a_{S} b^{2} T^{*} x M_{F}+b-16^{2} a_{S}^{3} b^{2} T^{* 3}\left(x T_{F}+T^{*}\right)=0 .
$$

We take the total derivative of Equation $(A .8)$ with respect to $x$ and $T^{*}$; then

$$
\begin{aligned}
\frac{d T^{*}}{d x} & =-\frac{T^{*}\left(M_{F}-16 a_{S}^{2} T^{* 2} T_{F}\right)}{x M_{F}-16 a_{S}^{2} T^{* 2} 3 x T_{F}-16 a_{S}^{2} T^{* 2} 4 T^{*}}=-\frac{T^{*} T_{F}\left(\frac{M_{F}}{T_{F}}-\frac{a_{S}}{b} \frac{T^{*}}{M^{*}}\right)}{x M_{F}-\frac{a_{S}}{b} \frac{T^{*}}{M^{*}}\left(3 x T_{F}+4 T^{*}\right)} \\
& =\frac{T^{*} T_{F}\left(\frac{M_{F}}{T_{F}}-\frac{M_{S}}{T_{S}}\right)}{2 M_{S}+M^{*}+\frac{M_{S}}{T_{S}} T^{*}},
\end{aligned}
$$

where the second and third equalities hold because of Equations $(A .7)$ and $(A .5)$, respectively. Therefore,

$$
\frac{d T^{*}}{d x} \gtreqless 0 \quad \text { if } \quad \frac{M_{F}}{T_{F}} \gtreqless \frac{M_{S}}{T_{S}} .
$$


By Equations $(A .7)$ and $(A .10)$, it follows that

$$
\frac{d M^{*}}{d x} \lesseqgtr 0 \quad \text { if } \quad \frac{M_{F}}{T_{F}} \gtreqless \frac{M_{S}}{T_{S}} .
$$

Thus, by Equations (A.6), (A.10), and (A.11),

$$
\frac{d\left(\frac{M_{S}}{T_{S}}\right)}{d x} \gtreqless 0 \quad \text { if } \quad \frac{M_{F}}{T_{F}} \gtreqless \frac{M_{S}}{T_{S}} .
$$

Equation (A.12) represents the finding that if the slope of the son's skill vector $\left(M_{S} / T_{S}\right)$ is smaller (or larger) than that of the father's $\left(M_{F} / T_{F}\right)$, as in Figure 1, then with an increase in $x$, the slope of the son's skill vector increases (or decreases). As a result, as $x$ increases, the slope of the son's skill vector gets close to that of the father's, i.e., $\partial \cos \theta / \partial x \geq 0$. Furthermore, we show :

Lemma $1 \partial \cos \theta / \partial x=0$ and $\cos \theta=1$, if $a_{S} /(1-\delta)=a_{F} / \delta$.

Proof of Lemma 1: By Equations $(A .1)$ and $(A .2)$,

$$
\frac{(1-\delta) / b}{\delta / a_{F}}=\left(\frac{M_{F}}{T_{F}}\right)^{2}
$$

Suppose that

$$
\frac{a_{S}}{1-\delta}=\frac{a_{F}}{\delta}
$$

Then, by Equations $(A .6),(A .13)$, and $(A .14)$,

$$
\left(\frac{M_{F}}{T_{F}}\right)^{2}=\left(\frac{M^{*}}{T^{*}}\right)\left(\frac{M_{S}}{T_{S}}\right) .
$$

Because of Equation (A.5), we can claim the following:

Claim 2 If either $\frac{M_{F}}{T_{F}} \gtreqless \frac{M^{*}}{T^{*}}$ or $\frac{M_{F}}{T_{F}} \gtreqless \frac{M_{S}}{T_{S}}$, then $\frac{M_{F}}{T_{F}} \gtreqless \frac{M_{S}}{T_{S}} \gtreqless \frac{M^{*}}{T^{*}}$.

By Claim 2, Equation (A.15) is equivalent to

$$
\frac{M_{F}}{T_{F}}=\frac{M^{*}}{T^{*}}=\frac{M_{S}}{T_{S}} .
$$

Thus, by Equations (A.12), Lemma 1 holds. That is, the father's skill vector and the son's skill vector have the same direction.

Q.E.D.

Proof of P1(ii): By Equations $(A .5)$ and $(A .9)$,

$$
\frac{d T_{S}}{d x}=T_{F}+\frac{d T^{*}}{d x}=\frac{T_{F}\left(2 M_{S}+M^{*}\right)+T^{*} M_{F}}{2 M_{S}+M^{*}+\frac{M_{S}}{T_{S}} T^{*}}>0 .
$$


By Equations $(A .5),(A .7)$, and (A.9),

$$
\frac{d M_{S}}{d x}=M_{F}+\frac{d M^{*}}{d x}=\frac{M_{F}\left(2 M_{S}+\frac{M_{S}}{T_{S}} T^{*}\right)+M^{*} T_{F} \frac{M_{S}}{T_{S}}}{2 M_{S}+M^{*}+\frac{M_{S}}{T_{S}} T^{*}}>0 .
$$

By Equations (A.17) and (A.18),

$$
\frac{\partial \omega_{S}}{\partial x}=\frac{1}{2}\left(T_{S} M_{S}\right)^{-1 / 2}\left(M_{S} \frac{d T_{S}}{d x}+T_{S} \frac{d M_{S}}{d x}\right)>0 .
$$

\section{A.2. Proof of Proposition P2}

Proof of P2(i): We now prove:

Lemma $3 \partial \cos \theta / \partial a_{S} \gtreqless 0$, if $\frac{a_{S}}{1-\delta} \lesseqgtr \frac{a_{F}}{\delta}$.

First, we make this claim:

Claim $4 \frac{M_{F}}{T_{F}} \gtreqless \frac{M_{S}}{T_{S}}$, if and only if $\frac{a_{S}}{1-\delta} \lesseqgtr \frac{a_{F}}{\delta}$.

Proof of Claim 4: (i) Suppose that $\frac{a_{S}}{1-\delta} \lesseqgtr \frac{a_{F}}{\delta}$. By Equations $(A .6)$ and (A.13), $\left(\frac{M_{F}}{T_{F}}\right)^{2} \gtreqless\left(\frac{M^{*}}{T^{*}}\right)\left(\frac{M_{S}}{T_{S}}\right)$. Therefore, because of Claim 2, $\frac{M_{F}}{T_{F}} \gtreqless \frac{M_{S}}{T_{S}} \gtreqless \frac{M^{*}}{T^{*}}$.

(ii) Suppose that $\frac{M_{F}}{T_{F}} \gtreqless \frac{M_{S}}{T_{S}}$. Then by Claim 2, $\frac{M_{F}}{T_{F}} \gtreqless \frac{M_{S}}{T_{S}} \gtreqless \frac{M^{*}}{T^{*}}$. Thus, $\left(\frac{M_{F}}{T_{F}}\right)^{2} \gtreqless\left(\frac{M^{*}}{T^{*}}\right)\left(\frac{M_{S}}{T_{S}}\right)$. Therefore, by Equations $(A .6)$ and $(A .13), \frac{a_{S}}{1-\delta} \lesseqgtr \frac{a_{F}}{\delta}$. Q.E.D.

Second, we show that if $a_{S}$ increases, then the slope of the son's skill vector $\left(M_{S} / T_{S}\right)$ also increases. By Equations (A.6) and (A.7),

$$
\frac{d\left(\frac{M_{S}}{T_{S}}\right)}{d a_{S}}=32 a_{S} T^{* 2}\left(1+\frac{a_{S}}{T^{*}} \frac{d T^{*}}{d a_{S}}\right) .
$$

We take the total derivative of Equation $(A .8)$ with respect to $a_{S}$ and $T^{*}$; we then have

$$
\frac{a_{S}}{T^{*}} \frac{d T^{*}}{d a_{S}}=\frac{x M_{F}-16 a_{S}^{2} T^{* 2} 3 T_{S}}{16 a_{S}^{2} T^{* 3}-\left(x M_{F}-16 a_{S}^{2} T^{* 2} 3 T_{S}\right)}=\frac{1}{\frac{16 a_{S}^{2} T^{* 3}}{x M_{F}-16 a_{S}^{2} T^{* 2} 3 T_{S}}-1} .
$$

By Equations $(A .6)$ and $(A .7)$,

$$
x M_{F}-16 a_{S}^{2} T^{* 2} 3 T_{S}=M_{S}-M^{*}-3 \frac{a_{S} T^{*}}{b M^{*}} T_{S}=-2 M_{S}-M^{*}<0 .
$$

By Equations (A.20) and (A.21),

$$
-1<\frac{a_{S}}{T^{*}} \frac{d T^{*}}{d a_{S}}<0
$$


By Equations (A.19) and (A.22),

$$
\frac{d\left(\frac{M_{S}}{T_{S}}\right)}{d a_{S}}>0 .
$$

Therefore, if the slope of the son's skill vector is initially smaller (or larger) than that of the

father's, as in Figure 1, that is, if $\frac{M_{F}}{T_{F}}>\frac{M_{S}}{T_{S}}$ (or $\frac{M_{F}}{T_{F}}<\frac{M_{S}}{T_{S}}$ ), then as $a_{S}$ increases, the slope of the son's skill vector moves closer to (or further away from) that of the father's and thus $\cos \theta$ increases (or decreases). That is,

$$
\frac{\partial \cos \theta}{\partial a_{S}} \gtrless 0, \quad \text { if } \quad \frac{M_{F}}{T_{F}} \gtrless \frac{M_{S}}{T_{S}} .
$$

The proof that $d \cos \theta / d a_{S}=0$ if $M_{F} / T_{F}=M_{S} / T_{S}$ is immediate. (The proof is available from the authors upon request.) Therefore, by Equation (A.24),

$$
\frac{\partial \cos \theta}{\partial a_{S}} \gtreqless 0, \quad \text { if } \quad \frac{M_{F}}{T_{F}} \gtreqless \frac{M_{S}}{T_{S}} .
$$

Because of Claim 4 and Equation (A.25), Lemma 3 holds. Therefore, P2(i) holds. Q.E.D. Proof of P2(ii): By Equations (A.7) and (A.22),

$$
\frac{d M^{*}}{d a_{S}}=-\frac{1}{16 a_{S}^{2} b T^{*}}\left(1+\frac{a_{S}}{T^{*}} \frac{d T^{*}}{d a_{S}}\right)<0 .
$$

By Equations (A.22) and (A.26),

$$
\frac{\partial \omega_{S}}{\partial a_{S}}=\frac{\omega_{S}}{2}\left(\frac{1}{T_{S}} \frac{d T^{*}}{d a_{S}}+\frac{1}{M_{S}} \frac{d M^{*}}{d a_{S}}\right)<0 .
$$

Q.E.D.

\section{A.3. Proof of Proposition P3}

Proof of P3(i): We numerically prove P3(i). In Appendix Figure 1, the white region shows the region of the parameter space $\left(a_{S}, a_{F}\right)$ that satisfies $\partial \cos \theta / \partial a_{F}<0$, given the parameters $x=1 / 2, b=1$, and $\delta=1 / 4,1 / 2$, and $3 / 4$. The straight line dividing the black and white regions represents $a_{S} /(1-\delta)=a_{F} / \delta$ and describes $\cos \theta=1$ and $\partial \cos \theta / \partial a_{F}=0$. The white region above the straight line satisfies $a_{S} /(1-\delta)<a_{F} / \delta$. Therefore, Appendix Figure 1 shows that P3(i) holds. For other parameter values, we also obtain $\partial \cos \theta / \partial a_{F}<0$ in the regions where $a_{S} /(1-\delta)<a_{F} / \delta$. The results are available from the authors upon request. 
Proof of P3(ii): First, we define the terms $T_{F, 1}, M_{F, 1}$, and $T_{F, 2}$ as follows:

$$
T_{F, 1}=T_{F}+\frac{d T_{F}}{d a_{F}} d a_{F} ; M_{F, 1}=M_{F}+\frac{d M_{F}}{d a_{F}} d a_{F} ; \text { and } T_{F, 2}=\frac{T_{F}}{M_{F}} M_{F, 1}=T_{F}+\frac{T_{F}}{M_{F}} \frac{d M_{F}}{d a_{F}} d a_{F} .
$$

Because $M_{F, 1} / T_{F, 2}=M_{F} / T_{F}$, the vector $\left(T_{F, 2}, M_{F, 1}\right)$ is on the vector $\left(T_{F}, M_{F}\right)$.

Second, given $T_{F, 1}, M_{F, 1}$, and $T_{F, 2}$, we next define $\left(T_{j}^{*}, M_{j}^{*}\right)$ and $\left(T_{S, j}, M_{S, j}\right)$ for $j=1,2$, which satisfy

$$
\frac{1}{2} T_{S, j}^{-1 / 2} M_{S, j}^{1 / 2}=2 a_{S} T_{j}^{*} ; \frac{1}{2} T_{S, j}^{1 / 2} M_{S, j}^{-1 / 2}=2 b M_{j}^{*} ; \text { and }\left(T_{S, j}, M_{S, j}\right)=\left(x T_{F, j}+T_{j}^{*}, x M_{F, 1}+M_{j}^{*}\right) .
$$

(This is similar to the way that $\left(T^{*}, M^{*}\right)$ and $\left(T_{S}, M_{S}\right)$ satisfy Equations $(A .3),(A .4)$, and $(A .5)$.) Reasoning in a way similar to our use of Equations $(A .3),(A .4)$, and $(A .5)$ to prove Equations $(A .6)$ and $(A .7)$, we can now use Equation $(A .28)$ to show that, for $j=1$ and 2 , it is true that

$$
\frac{M_{S, j}}{T_{S, j}}=\frac{x M_{F, 1}+M_{j}^{*}}{x T_{F, j}+T_{j}^{*}}=\frac{a_{S}}{b} \frac{T_{j}^{*}}{M_{j}^{*}}, \text { and } 16 a_{S} b T_{j}^{*} M_{j}^{*}=1 .
$$

Third, we now prove that

$$
\begin{aligned}
& \omega_{S}\left(T_{S, 1}, M_{S, 1}\right) \leq \omega_{S}\left(T_{S, 2}, M_{S, 2}\right) \leq \omega_{S}\left(T_{S}, M_{S}\right) \quad \text { if } d a_{F}>0 ; \\
& \omega_{S}\left(T_{S, 1}, M_{S, 1}\right) \geq \omega_{S}\left(T_{S, 2}, M_{S, 2}\right) \geq \omega_{S}\left(T_{S}, M_{S}\right) \text { if } d a_{F}<0,
\end{aligned}
$$

where these equalities hold if $x=0$.

(i) The proof that $\omega_{S}\left(T_{S, 2}, M_{S, 2}\right) \leq \omega_{S}\left(T_{S}, M_{S}\right)$ if $d a_{F}>0$ (the equality holds if $x=0$ ) in Equation (A.30):

The proof is organized in three steps. Step 1 characterizes the father's skill vector $\left(T_{F}, M_{F}\right)$. Step 2 shows that an increase in $a_{F}$ reduces $M_{F}$ skills. This is because the iso-wage curve is Cobb-Douglas and the iso-cost curve is elliptical; the income effect of $a_{F}$ on $M_{F}$ thus dominates its substitution effect. As a result, $\left(T_{F, 2}, M_{F, 1}\right)=h\left(T_{F}, M_{F}\right)$ for $h \in(0,1)$. Step 3 concludes by using Step 2 and P1(ii).

Step 1: By Equations $(A .1)$ and $(A .2)$,

$$
T_{F}=\frac{1}{2} a_{F}^{-\frac{1+\delta}{2}} b^{-\frac{1-\delta}{2}}(1-\delta)^{\frac{1-\delta}{2}} \delta^{\frac{1+\delta}{2}}, \text { and } M_{F}=\frac{1}{2} a_{F}^{-\frac{\delta}{2}} b^{-\left(1-\frac{\delta}{2}\right)}(1-\delta)^{1-\frac{\delta}{2}} \delta^{\frac{\delta}{2}} .
$$

Step 2: By Equation (A.32), $d M_{F} / d a_{F}<0$. Because (i) the vector $\left(T_{F, 2}, M_{F, 1}\right)$ is on the vector $\left(T_{F}, M_{F}\right)$, (ii) $d a_{F}>0$, and (iii) $d M_{F} / d a_{F}<0$, it follows that $\left(T_{F, 2}, M_{F, 1}\right)=h\left(T_{F}, M_{F}\right)$ for $h \in(0,1)$. 
Step 3: The first, second, and fourth equalities in (A.33) hold because of Equation (A.28), Step 2, and Equation (A.5), respectively, while the third inequality holds because of P1(ii):

$$
\begin{aligned}
\omega_{S}\left(T_{S, 2}, M_{S, 2}\right) & =\omega_{S}\left(x T_{F, 2}+T_{2}^{*}, x M_{F, 1}+M_{2}^{*}\right)=\omega_{S}\left(h x T_{F}+T_{2}^{*}, h x M_{F}+M_{2}^{*}\right) \\
& \leq \omega_{S}\left(x T_{F}+T^{*}, x M_{F}+M^{*}\right)=\omega_{S}\left(T_{S}, M_{S}\right)
\end{aligned}
$$

where $h \in(0,1)$ and the equality in the inequality holds if $x=0$.

(ii) The proof that $\omega_{S}\left(T_{S, 1}, M_{S, 1}\right) \leq \omega_{S}\left(T_{S, 2}, M_{S, 2}\right)$ if $d a_{F}>0$ (the equality holds if $x=0$ ) in Equation (A.30):

The proof is organized in four steps. Step 1 shows that an increase in $a_{F}$ reduces both $T_{F}$ and $M_{F}$ skills because of the complementarity between these skills, but the decrease in the $T_{F}$ skill $\left(=T_{F}-T_{F, 1}\right)$ is greater than the decrease in the $M_{F}$ skill multiplied by $T_{F} / M_{F}\left(=T_{F}-T_{F, 2}\right)$ because of the substitution effect between these skills. Therefore, the new origin of the son's cost function $\left(x T_{F, 1}, x M_{F, 1}\right)$ satisfies this inequality: $x T_{F, 1}<x T_{F, 2}$. Steps 2 and 3 show that the son's skills $T_{S, 1}$ and $M_{S, 1}$ associated with $\left(x T_{F, 1}, x M_{F, 1}\right)$ as the origin of his cost function are smaller than $T_{S, 2}$ and $M_{S, 2}$ associated with $\left(x T_{F, 2}, x M_{F, 1}\right)$ as the origin, respectively. Step 4 concludes.

Step 1: By Equation (A.32),

$$
\frac{d T_{F}}{d a_{F}}<\frac{T_{F}}{M_{F}} \frac{d M_{F}}{d a_{F}}<0 .
$$

Because $d a_{F}>0$ and because of Equations $(A .27)$ and $(A .34), T_{F, 1}<T_{F, 2}$. Therefore,

$$
\left(T_{F, 1}, M_{F, 1}\right)=\left(k T_{F, 2}, M_{F, 1}\right) \text { for } k \in(0,1) \text {, and }\left(T_{F, 2}, M_{F, 1}\right)=\left(k T_{F, 2}, M_{F, 1}\right) \text { for } k=1 \text {. }
$$

Step 2: By Equations (A.28) and (A.35),

$$
\left\{\begin{array}{l}
T_{S, 1}=x T_{F, 1}+T_{1}^{*}=x k T_{F, 2}+T_{1}^{*} \text { for } k \in(0,1) \\
T_{S, 2}=x T_{F, 2}+T_{2}^{*}=x k T_{F, 2}+T_{2}^{*} \text { for } k=1 .
\end{array}\right.
$$

When we substitute Equation (A.36) into Equation $(A .29)$, for $j=1,2$ (such that if $j=1$, then $k \in(0,1)$; and if $j=2$, then $k=1)$, it then follows that

$$
\frac{M_{S, j}}{T_{S, j}}=\frac{x M_{F, 1}+M_{j}^{*}}{x k T_{F, 2}+T_{j}^{*}}=\frac{a_{S}}{b} \frac{T_{j}^{*}}{M_{j}^{*}}, \text { and } 16 a_{S} b T_{j}^{*} M_{j}^{*}=1 .
$$

In Appendix A.1, in the proof of P1(i), we used Equation $(A .6)$ and $(A .7)$ to obtain Equation (A.9). Similarly, we now use Equation $(A .37)$ to obtain this equation:

$$
\frac{d T_{j}^{*}}{d k}=-\frac{16 a_{S}^{2} T_{j}^{* 3} x T_{F, 2}}{2 M_{S, j}+M_{j}^{*}+\frac{M_{S, j}}{T_{S, j}} T_{j}^{*}} \leq 0
$$


where the equality in the inequality holds if $x=0$. Hence, by Equations $(A .36)$ and $(A .38)$,

$$
\frac{d T_{S, j}}{d k}=x T_{F, 2}+\frac{d T_{j}^{*}}{d k}=\frac{x T_{F, 2}\left(2 M_{S, j}+M_{j}^{*}\right)}{2 M_{S, j}+M_{j}^{*}+\frac{M_{S, j}}{T_{S, j}} T_{j}^{*}} \geq 0
$$

where the equality in the inequality holds if $x=0$. Thus, by Equations $(A .36)$ and $(A .39)$,

$$
T_{S, 1} \leq T_{S, 2} \quad \text { (the equality holds if } x=0 \text { ) }
$$

Step 3: Because of Equations $(A .28)\left(M_{S, j}=x M_{F, 1}+M_{j}^{*}\right.$ for $\left.j=1,2\right),(A .37)$, and $(A .38)$, it follows that $\frac{d M_{S, j}}{d k}=\frac{d M_{j}^{*}}{d k}=-\frac{1}{16 a_{S} b T_{j}^{* 2}} \frac{d T_{j}^{*}}{d k} \geq 0$, where the equality in the inequality holds if $x=0$. Therefore,

$$
\left.M_{S, 1} \leq M_{S, 2} \quad \text { (the equality holds if } x=0\right) .
$$

Step 4: By Equations (A.40) and (A.41),

$$
\left.\omega_{S}\left(T_{S, 1}, M_{S, 1}\right) \leq \omega_{S}\left(T_{S, 2}, M_{S, 2}\right) \quad \text { (the equality holds if } x=0\right)
$$

By Equations (A.33) and (A.42), we conclude that Equation (A.30) holds.

(iii) The proof of Equation (A.31):

The proof is constructed along lines similar to the proof of Equation (A.30) in (i) and (ii).

We conclude that P3(ii) holds.

Q.E.D.

\section{A.4. Proof of Proposition P4}

We prove that (i) $\frac{\partial \omega_{S}\left(T_{S}, M_{S}\right)}{\partial a_{F}} \leq \frac{\partial \omega_{S}\left(T_{S}, M_{S}\right)}{\partial T_{S}} \frac{\partial T_{S}}{\partial a_{F}}$ and (ii) $\frac{\partial \omega_{S}\left(T_{S}, M_{S}\right)}{\partial T_{S}} \frac{\partial T_{S}}{\partial a_{F}} \leq \frac{\partial \omega_{S}\left(T_{S}, M_{S}\right)}{\partial T_{S}} \frac{\partial T_{S}}{\partial T_{F}} \frac{\partial T_{F}}{\partial a_{F}} \leq 0$, where these equalities hold if $x=0$. We use the variables $T_{F, 1}, M_{F, 1}, T_{F, 2}, T_{j}^{*}, M_{j}^{*}, T_{S, j}$, and $M_{S, j}$ for $j=1,2$; these variables are defined in Appendix A.3, in the proof of P3(ii).

(i) The proof that $\frac{\partial \omega_{S}\left(T_{S}, M_{S}\right)}{\partial a_{F}} \leq \frac{\partial \omega_{S}\left(T_{S}, M_{S}\right)}{\partial T_{S}} \frac{\partial T_{S}}{\partial a_{F}}$ (the equality holds if $x=0$ ).

First, we prove that $\partial M_{S} / \partial a_{F} \leq 0$ for two cases: Case (1) where $d a_{F}>0$ and Case (2) where $d a_{F}<0$.

In Case (1) where $d a_{F}>0$ : Because of Equation (A.28) and Step 2 in Part (i) of the proof of P3(ii) in Appendix A.3, it follows that $M_{S, 2}=x M_{F, 1}+M_{2}^{*}=h x M_{F}+M_{2}^{*}$ for $h \in(0,1)$. By reasoning similar to Step 3 in Part (i) of the proof of P3(ii) in Appendix A.3, we have $h x M_{F}+M_{2}^{*} \leq x M_{F}+M^{*}=M_{S}$, where the equality in the inequality holds if $x=0$. Hence,

$$
\left.M_{S, 2} \leq M_{S} \quad \text { (the equality holds if } x=0\right)
$$


By Equations (A.41) and (A.43),

$$
\left.M_{S, 1} \leq M_{S} \quad \text { (the equality holds if } x=0\right)
$$

By the definitions of $T_{F, 1}, M_{F, 1}$, and $M_{S, 1}$ in Equations $(A .27)$ and $(A .28)$, Equation $(A .44)$ implies

$$
\left.\frac{\partial M_{S}}{\partial a_{F}} \leq 0 \quad \text { (the equality holds if } x=0\right) \text {. }
$$

In Case (2) where $d a_{F}<0$ : The proof of Equation $(A .45)$ is constructed along lines similar to the proof of Case (1) where $d a_{F}>0$. Therefore, Equation (A.45) holds for both Cases (1) and (2). Accordingly, because $\partial \omega_{S}\left(T_{S}, M_{S}\right) / \partial M_{S}>0$ and Equation $(A .45)$ holds, it follows that:

$$
\frac{\partial \omega_{S}\left(T_{S}, M_{S}\right)}{\partial a_{F}}=\frac{\partial \omega_{S}\left(T_{S}, M_{S}\right)}{\partial T_{S}} \frac{\partial T_{S}}{\partial a_{F}}+\frac{\partial \omega_{S}\left(T_{S}, M_{S}\right)}{\partial M_{S}} \frac{\partial M_{S}}{\partial a_{F}} \leq \frac{\partial \omega_{S}\left(T_{S}, M_{S}\right)}{\partial T_{S}} \frac{\partial T_{S}}{\partial a_{F}},
$$

where the equality in the inequality holds if $x=0$.

(ii) The proof that $\frac{\partial \omega_{S}\left(T_{S}, M_{S}\right)}{\partial T_{S}} \frac{\partial T_{S}}{\partial a_{F}} \leq \frac{\partial \omega_{S}\left(T_{S}, M_{S}\right)}{\partial T_{S}} \frac{\partial T_{S}}{\partial T_{F}} \frac{\partial T_{F}}{\partial a_{F}} \leq 0$ (the equalities hold if $x=0$ ).

The proof is organized in seven steps. In Step 1, we define $\left(T_{S, 3}, M_{S, 3}\right)$ and then document that $T_{S, 3}-T_{S}=\frac{\partial T_{S}}{\partial T_{F}} \frac{\partial T_{F}}{\partial a_{F}}$ and $T_{S, 1}-T_{S}=\partial T_{S} / \partial a_{F}$, where $T_{S, 1}$ is defined as in Equation (A.28). In Step 2, we characterize $\left(T_{S, 3}, M_{S, 3}\right)$. In Step 3, we show that $T_{S, 1}$ is smaller than $T_{S, 3}$. In Step 4, we show that $T_{S, 3}$ is smaller than $T_{S}$. In Steps 5 and 6 , we combine Steps 1 to 4 to show that $\partial T_{S} / \partial a_{F} \leq \frac{\partial T_{S}}{\partial T_{F}} \frac{\partial T_{F}}{\partial a_{F}} \leq 0$. In Step 7, we conclude.

Step 1: We define $T_{F, 1}$ in Equation $(A .27)$. Given $T_{F, 1}$ and $M_{F}$, we define $\left(T_{3}^{*}, M_{3}^{*}\right)$ and $\left(T_{S, 3}, M_{S, 3}\right)$, which satisfy:

$$
\frac{1}{2} T_{S, 3}^{-1 / 2} M_{S, 3}^{1 / 2}=2 a_{S} T_{3}^{*}, \frac{1}{2} T_{S, 3}^{1 / 2} M_{S, 3}^{-1 / 2}=2 b M_{3}^{*} \text {, and }\left(T_{S, 3}, M_{S, 3}\right)=\left(x T_{F, 1}+T_{3}^{*}, x M_{F}+M_{3}^{*}\right) .
$$

By the definitions of $T_{F, 1}$ and $T_{S, 3}$,

$$
\frac{\partial T_{S}}{\partial T_{F}} \frac{\partial T_{F}}{\partial a_{F}}=T_{S, 3}-T_{S}
$$

Since we define $\left(T_{F, 1}, M_{F, 1}\right)$ in Equation $(A .27)$, and then define $T_{S, 1}$ in Equation $(A .28)$,

$$
\frac{\partial T_{S}}{\partial a_{F}}=T_{S, 1}-T_{S}
$$

Step 2: Reasoning in a way similar to our use of Equation (A.28) to prove Equation (A.29), we can use Equation $(A .47)$ to show that

$$
\frac{M_{S, 3}}{T_{S, 3}}=\frac{x M_{F}+M_{3}^{*}}{x T_{F, 1}+T_{3}^{*}}=\frac{a_{S}}{b} \frac{T_{3}^{*}}{M_{3}^{*}}, \text { and } 16 a_{S} b T_{3}^{*} M_{3}^{*}=1 .
$$


Step 3: We prove that $\partial T_{S} / \partial a_{F} \leq \frac{\partial T_{S}}{\partial T_{F}} \frac{\partial T_{F}}{\partial a_{F}} \leq 0$ for two cases: Case (1) where $d a_{F}>0$ and Case (2) where $d a_{F}<0$.

In Case (1) where $d a_{F}>0$ : Because of Equations $(A .27)$ and $(A .34), M_{F}=l M_{F, 1}$ for $l>1$. Therefore by Equations $(A .29)$ and $(A .50)$, for $j=1,3$ (such that if $j=1$, then $l=1$; and if $j=3$, then $l>1$ ), it then follows that

$$
\frac{M_{S, j}}{T_{S, j}}=\frac{x l M_{F, 1}+M_{j}^{*}}{x T_{F, 1}+T_{j}^{*}}=\frac{a_{S}}{b} \frac{T_{j}^{*}}{M_{j}^{*}}, \text { and } 16 a_{S} b T_{j}^{*} M_{j}^{*}=1 .
$$

We used Equation (A.37) to obtain Equation (A.39). Similarly, we now use Equation $(A .51)$ to obtain the following equation:

$$
\frac{d T_{S, j}}{d l}=\frac{x T_{j}^{*} M_{F, 1}}{2 M_{S, j}+M_{j}^{*}+\frac{M_{S, j}}{T_{S, j}} T_{j}^{*}} \geq 0
$$

where the equality in the inequality holds if $x=0$. Therefore,

$$
\left.T_{S, 1} \leq T_{S, 3} \quad \text { (the equality holds if } x=0\right)
$$

Step 4: Because of Equations $(A .27)$ and $(A .34), T_{F, 1}=q T_{F}$ for $q \in(0,1)$. Therefore, by Equation $(A .50)$,

$$
\frac{M_{S, 3}}{T_{S, 3}}=\frac{x M_{F}+M_{3}^{*}}{x q T_{F}+T_{3}^{*}}=\frac{a_{S}}{b} \frac{T_{3}^{*}}{M_{3}^{*}}, \text { and } 16 a_{S} b T_{3}^{*} M_{3}^{*}=1 .
$$

We used Equation (A.37) to obtain Equation (A.40). Similarly, we now use Equations (A.6), $(A .7)$, and $(A .54)$ to obtain this equation:

$$
\left.T_{S, 3} \leq T_{S} \quad \text { (the equality holds if } x=0\right)
$$

Step 5: By Equations (A.48), (A.49), (A.53), and (A.55),

$$
\frac{\partial T_{S}}{\partial a_{F}} \leq \frac{\partial T_{S}}{\partial T_{F}} \frac{\partial T_{F}}{\partial a_{F}} \leq 0 \quad(\text { the equalities hold if } x=0)
$$

Step 6: In Case (2) where $d a_{F}<0$ : The proof of Equation $(A .56)$ is constructed along lines similar to the proof in Steps 3 to 5 .

Step 7: Because $\partial \omega_{S}\left(T_{S}, M_{S}\right) / \partial T_{S}>0$ and Equation $(A .56)$ holds,

$$
\left.\frac{\partial \omega_{S}\left(T_{S}, M_{S}\right)}{\partial T_{S}} \frac{\partial T_{S}}{\partial a_{F}} \leq \frac{\partial \omega_{S}\left(T_{S}, M_{S}\right)}{\partial T_{S}} \frac{\partial T_{S}}{\partial T_{F}} \frac{\partial T_{F}}{\partial a_{F}} \leq 0 \quad \text { (the equalities hold if } x=0\right) .
$$

By Equations (A.46) and (A.57), P4 holds.

Q.E.D. 


\section{Numerical Results for P4:}

Let

$$
R 1=\frac{\frac{\partial \omega_{S}\left(T_{S}, M_{S}\right)}{\partial T_{S}} \frac{\partial T_{S}}{\partial a_{F}}}{\frac{\partial \omega_{S}\left(T_{S}, M_{S}\right)}{\partial a_{F}}} \quad \text { and } \quad R 2=\frac{\frac{\partial \omega_{S}\left(T_{S}, M_{S}\right)}{\partial T_{S}} \frac{\partial T_{S}}{\partial T_{F}} \frac{\partial T_{F}}{\partial a_{F}}}{\frac{\partial \omega_{S}\left(T_{S}, M_{S}\right)}{\partial a_{F}}} .
$$

Appendix Figure 2 Panel A displays the ratios $R 1$ and $R 2$ on an $\left(a_{S}, a_{F}\right)$ plane, given $x=1 / 2$, $\delta=1 / 4$, and $b=1$. Appendix Figure 2 Panel B displays these ratios when $a_{S}$ is set to one and Panel $\mathrm{C}$ displays them when $a_{F}$ is set to one. Both ratios $R 1$ and $R 2$ are smaller than unity and $R 1$ is greater than $R 2$, which support Equation (7) because $\partial \omega_{S}\left(T_{S}, M_{S}\right) / \partial a_{F}<0$. The ratio $R 1$ is in the range of $0.5-0.75$, whereas the ratio $R 2$ is in the range of $0.3-0.75$, unless $a_{F}$ and $a_{S}$ are close to zero. For other parameter values, we obtain the same conclusion; the results are available from the authors upon request. 
(a) $\delta=1 / 4$

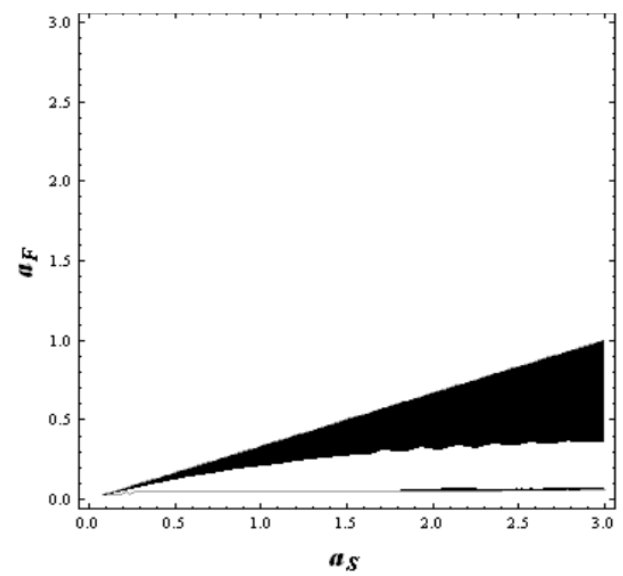

(b) $\delta=1 / 2$

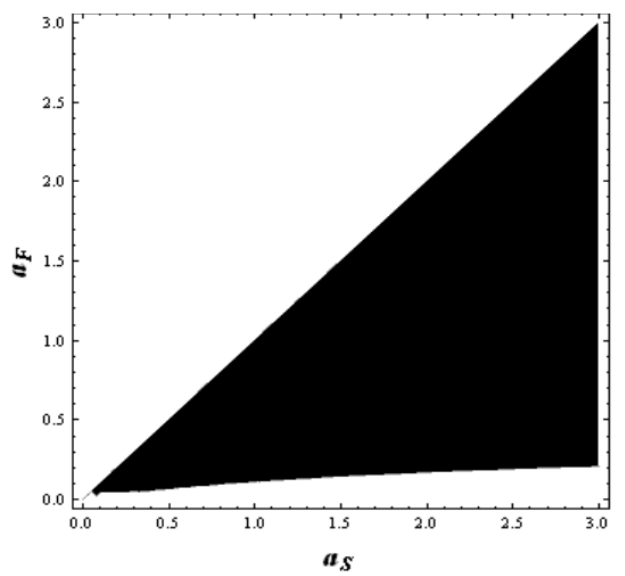

(c) $\delta=3 / 4$

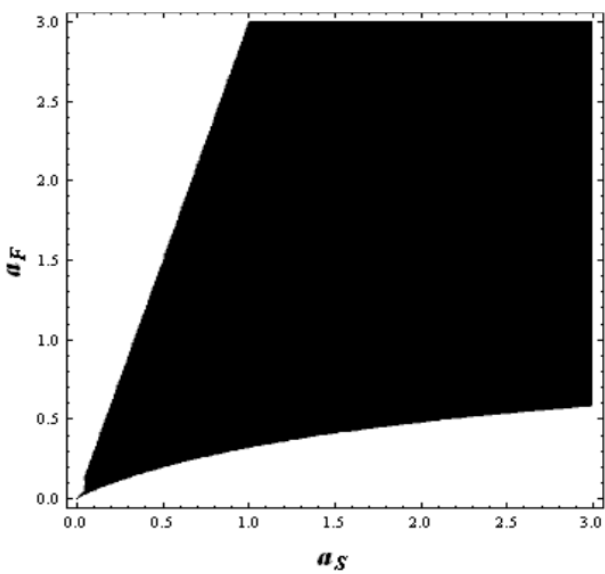

Note: The black region indicates the region of the parameter space $\left(a_{S}, a_{F}\right)$ that satisfies $\partial \cos \theta / \partial a_{F} \geq 0$, and the white region indicates the region that satisfies $\partial \cos \theta / \partial a_{F}<0$. The straight line dividing the black and white regions is $\delta / a_{F}=(1-\delta) / a_{S}$, and the white region above the straight line satisfies $\delta / a_{F}<(1-\delta) / a_{S}$. The parameter values are set as: $x=1 / 2$ and $b=1$.

\section{Appendix Figure 2: Ratios R1 and R2 in Proposition P4}

Panel A. R1 (upper surface) and R2 (lower surface) on an $\left(a_{s}, a_{F}\right)$ plane

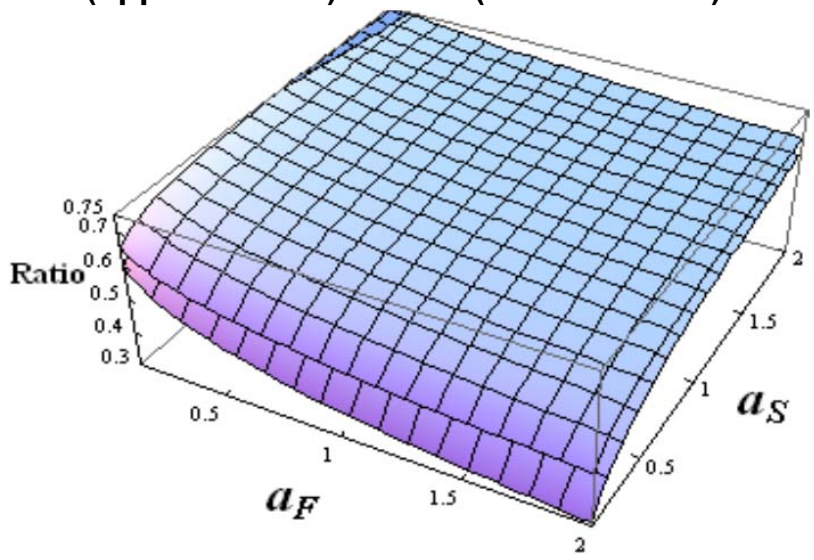

Panel B. R1 (solid line) and R2 (dotted line) when $a_{s}$ is set to 1

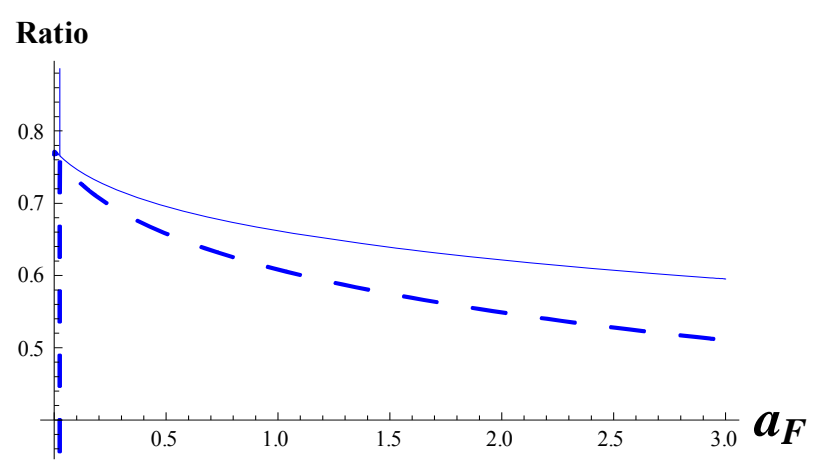

Panel C. R1 (solid line) and R2 (dotted line) when $a_{F}$ Ratio

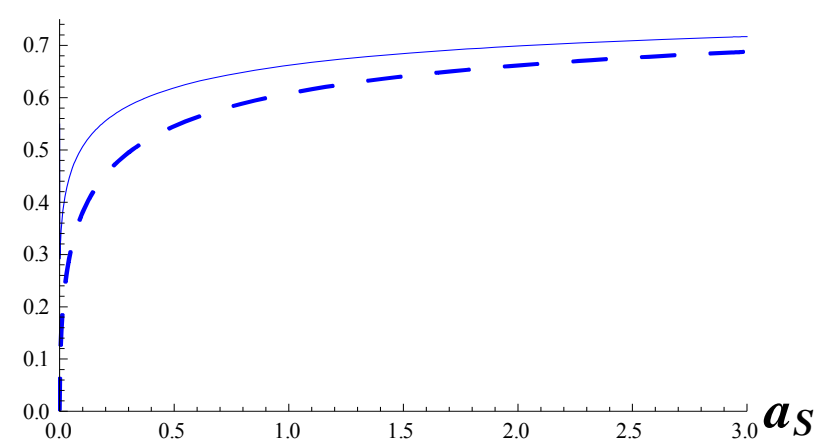

Note: Ratios $\mathrm{R} 1$ and $\mathrm{R} 2$ are defined as: $\quad R 1=\frac{\frac{\partial \omega_{S}\left(T_{S}, M_{S}\right)}{\partial T_{S}} \frac{\partial T_{S}}{\partial a_{F}}}{\frac{\partial \omega_{S}\left(T_{S}, M_{S}\right)}{\partial a_{F}}}$ and $R 2=\frac{\frac{\partial \omega_{S}\left(T_{S}, M_{S}\right)}{\partial T_{S}} \frac{\partial T_{S}}{\partial T_{F}} \frac{\partial T_{F}}{\partial a_{F}}}{\frac{\partial \omega_{S}\left(T_{S}, M_{S}\right)}{\partial a_{F}}}$. The parameter values are set
as: $\mathrm{x}=1 / 2, \delta=1 / 4$, and $\mathrm{b}=1$. 